Supramolecular methods: the 8-hydroxypyrene-1,3,6-trisulfonic acid (HPTS) transport assay

Alexander M. Gilchrist, ${ }^{1}$ Patrick Wang, ${ }^{1}$ Israel Carreira-Barral, ${ }^{2}$ Daniel Alonso-Carrillo, ${ }^{2}$ Xin $\mathrm{Wu},{ }^{1}$ Roberto Quesada, ${ }^{* 2}$ and Philip A. Gale ${ }^{* 1,3}$

${ }^{1}$ School of Chemistry, The University of Sydney, NSW 2006, Australia

${ }^{2}$ Departmento de Química, Universidad de Burgos, 09001 Burgos, Spain

${ }^{3}$ The University of Sydney Nano Institute (Sydney Nano), The University of Sydney, Sydney 2006, Australia

*rquesada@ubu.es

*philip.gale@sydney.edu.au 


\section{Supramolecular methods: the 8-hydroxypyrene-1,3,6-trisulfonic acid (HPTS) transport assay}

The vesicular anion transport activity assay, which uses 8-hydroxypyrene-1,3,6trisulfonic acid to monitor the internal $\mathrm{pH}$ of the vesicles (the HPTS assay), is a widely used technique for analysing the activity of anionophore facilitated transport across a phospholipid membrane. This methods paper describes the stepwise technique to conduct this transport assay, detailing both the perks and pitfalls of using this method to determine the activity of an anionophore and the transport mechanism.

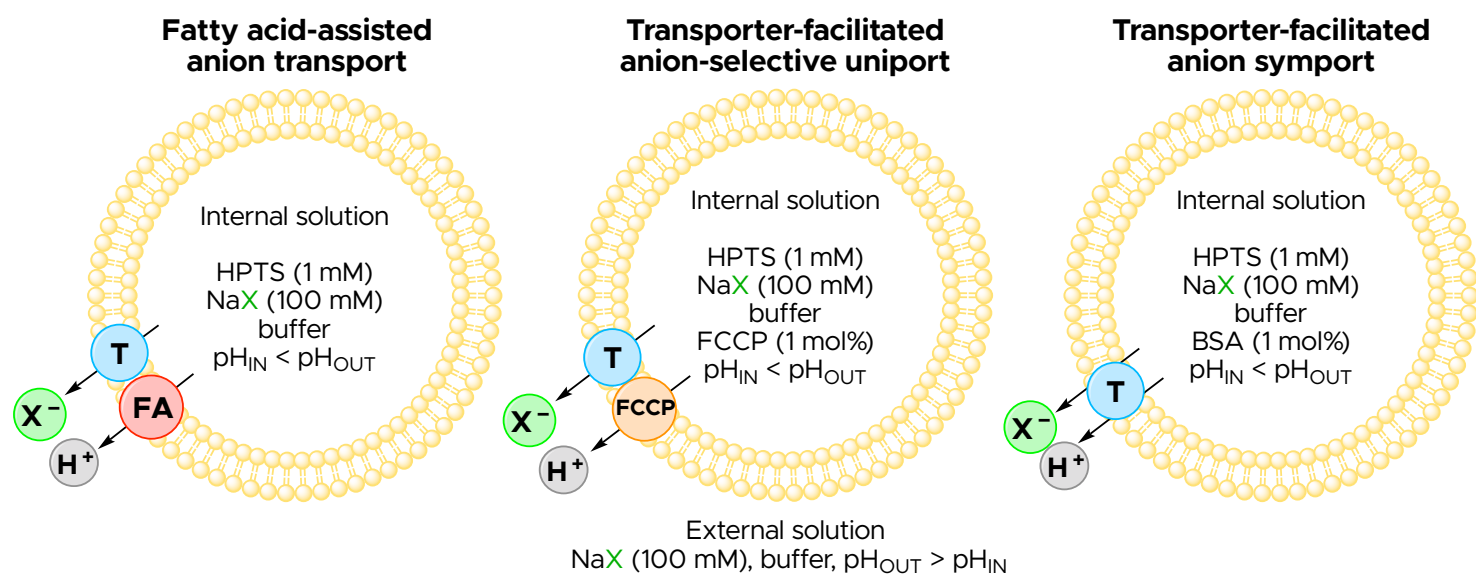

Keywords: supramolecular chemistry, anion transport, HPTS assay, vesicles

\section{Introduction:}

In Nature, the binding and transport of ions has a vital function in many fundamental systems. More specifically, anions have crucial roles within many biological processes, such as maintaining neutrality in charged transport processes, ${ }^{1}$ maintaining intra- and extracellular $\mathrm{pH},{ }^{2}$ and controlling cellular volumes. ${ }^{3}$ A number of diseases known as channelopathies, including cystic fibrosis (CF) and Bartter syndrome, are caused by the dysregulation or inhibition of ion transport through membrane-embedded ion channels. ${ }^{4}$, 
Anion transporters offer the possibility of opening up new ways of treating diseases such as CF by replacing the function of the faulty ion channels (an approach known as a channel replacement therapy) or disturbing both ionic and $\mathrm{pH}$ gradients across cancer cell membranes and within cells, triggering cell death ${ }^{6,7}$ To this end, a major goal of transporter design has been the enhancement of transport activity, thereby creating more potent systems. However, recently the focus of synthetic ionophore research has shifted from gradual increases in small molecule binding and transport efficiencies to detailed investigations into the mechanism of transport. The selectivity of the transporter for binding anions over protons and the mechanism of proton transport by anionophores has been suggested to correlate with cytotoxicity. ${ }^{8,9}$ Therefore, by considering the mechanism of transport and intrinsic anion selectivity when applying transporter design principles to new transporters, there is great potential for such research to be used in therapeutic applications. This shift in the design process has been exemplified by a series of biotin[6]uril esters reported by Lisbjerg et al., which incorporated soft $\mathrm{C}-\mathrm{H} \cdots \mathrm{X}^{-}$bonding moieties and demonstrated $\mathrm{Cl}^{-}>\mathrm{HCO}_{3}{ }^{-}$selective transport. ${ }^{10}$

Synthetic vesicles composed of phospholipids are often used as model cells in anion transport experiments. The modification and wide adoption of this practical and flexible technique has provided a multitude of assays to determine the activity of a transporter in a lipid bilayer. Assays that rely on an anion exchange process, such as the chloride/nitrate exchange assay or the lucigenin fluorescence quenching assay, ${ }^{11}$ have been widely used to analyse the anion binding and transport of synthetic transporters.

To study the efficiency of receptor-mediated transport of non-basic anions (or basic anions whose conjugate acids are not membrane permeable), an assay incorporating the $\mathrm{pH}$-sensitive fluorescent probe 8-hydroxypyrene-1,3,6-trisulfonic acid 
(HPTS) encapsulated within synthetic vesicles composed of a single lipid bilayer (unilamellar) using commercial phospholipids such as 1-palmitoyl-2-oleoyl-sn-glycero3-phosphocholine (POPC) may be used. ${ }^{12}$ This assay employs HPTS, also known as pyranine, to monitor intravesicular $\mathrm{pH}$, and by using a variety of different conditions, the relationship between anion transport and $\mathrm{pH}$ dissipation across the membrane can be determined together with the mechanism of anion transport. Additionally, HPTS is not only useful for monitoring anion transport, but it can also be used as a sensitive vesicle leakage marker. ${ }^{13}$ As with other vesicular assays, the HPTS assay relies on the impermeable nature of the lipid bilayer to charged species such as hydrophilic chloride anions that possess significant dehydration penalties. ${ }^{14}$

\section{Experiments:}

\section{The HPTS assay:}

In general, the HPTS assay employs synthetic unilamellar vesicles $(200 \mathrm{~nm})$ composed of POPC or EYPC containing HPTS $(1 \mathrm{mM})$ and are suspended in and contain a solution of $\mathrm{NaCl}(100 \mathrm{mM})$ buffered to $\mathrm{pH} 7.0$ using 4-(2-hydroxyethyl)-1piperazineethanesulfonic acid (HEPES, $10 \mathrm{mM}$ ). ${ }^{12,}{ }^{15}$ A fluorimeter is used to monitor changes in HPTS fluorescence emission due to dissipation of the $\mathrm{pH}$ gradient by transporter-facilitated $\mathrm{Cl}^{-} / \mathrm{H}^{+}$symport or $\mathrm{Cl}^{-} / \mathrm{OH}^{-}$antiport (Figure 1). Transporter activity can then be assessed according to the subsequent $\mathrm{pH}$ dissipation across the lipid bilayer. However, it should be stated that due to the intrinsic flexibility of this assay, conditions like the type of phospholipid, liposome size, $\mathrm{pH}$, buffer systems, salts, and solvent media, can be changed to suit the needs of systems being tested. 


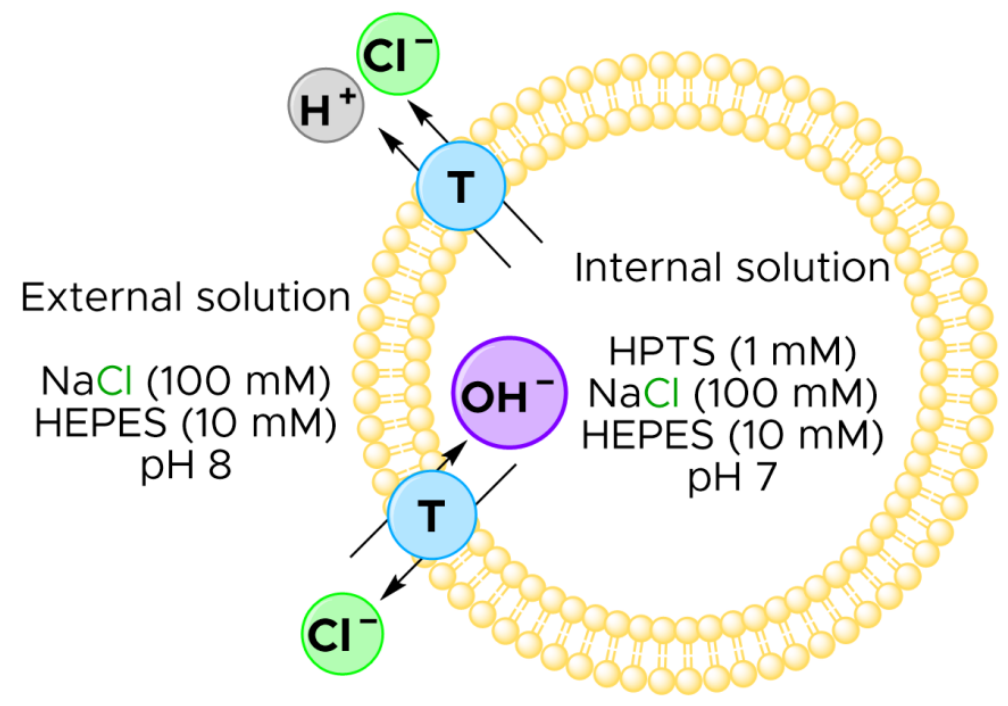

Figure 1. A model HPTS assay system where a $\mathrm{Cl}^{-} / \mathrm{H}^{+}$symport and $\mathrm{Cl}^{-} / \mathrm{OH}^{-}$antiport $\left(\mathrm{Cl}^{-}=\right.$green, $\mathrm{H}^{+}=$grey, $\mathrm{OH}^{-}=$purple $)$mechanism is facilitated when a small molecule transporter ( $\mathrm{T}$, blue) is added to a synthetic vesicle (yellow) during the HPTS assay.

By performing Hill analysis on the data obtained from the HPTS assay, the activity $\left(\mathrm{EC}_{50}\right)$ of either $\mathrm{H}^{+} / \mathrm{Cl}^{-}$symport or $\mathrm{OH}^{-} / \mathrm{Cl}^{-}$antiport can be determined. However, the rate-limiting step in this process may not be chloride transport as the anion transporters of different classes might show selectivity for transporting chloride over protons or hydroxide. Therefore, a measurement of the $\mathrm{HCl}$ transport activity of a particular anionophore may underestimate its true ability to facilitate chloride transport. ${ }^{14}$ Additionally, it should be noted that commercial lipids such as POPC or EYPC contain free fatty acid impurities, which are incorporated into the vesicular membranes prepared from those lipids. ${ }^{16}$ In particular, a difference in the amount of fatty acid impurities between batches of commercial lipids can result in variable proton transport rates mediated via a fatty acid flip-flop mechanism. ${ }^{16}$ This problem may lead to batch-dependent data inconsistency; however, this can be mitigated by adding free fatty acids (1-2 mol\% with respect to the lipid concentration) to the vesicles to maximise the fatty acid-dependent $\mathrm{H}^{+}$transport rate. 


\section{Exploring anion vs proton/hydroxide selectivity:}

The HPTS assay can be modified to determine the chloride (or other anions) vs proton or hydroxide transport selectivity due to the potential for $\mathrm{H}^{+}$or $\mathrm{OH}^{-}$transport to be the rate-limiting step.
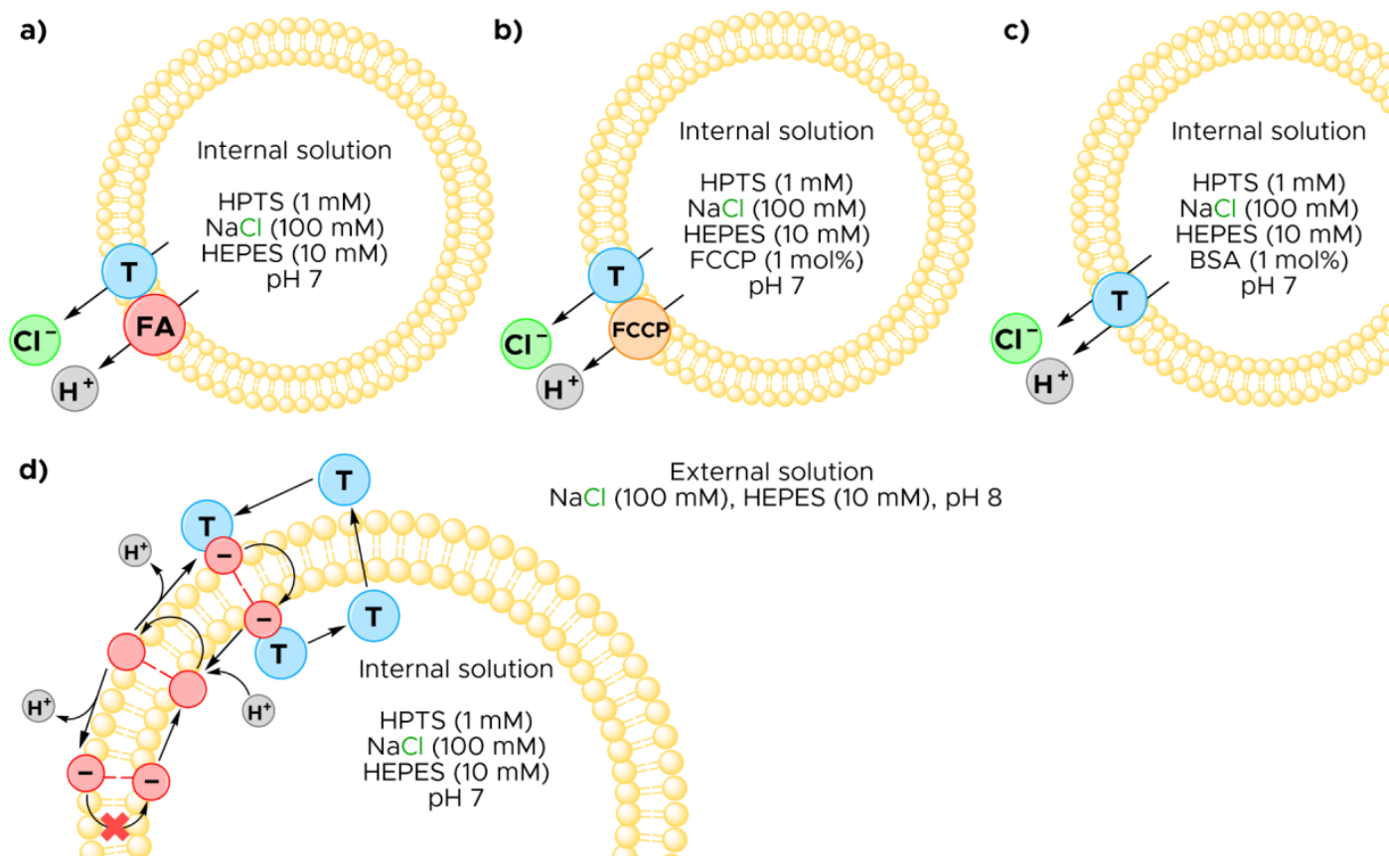

Figure 2. The three HPTS transport assay conditions the transporter ( $T$, blue) is tested in: a) untreated vesicles (yellow) to observe fatty acid (FA, red) assisted transport, b) weak acid protonophore (FCCP, orange) treated vesicles to observe selective chloride transport, c) fatty acid-free vesicles (treated with BSA) to observe receptor-facilitated $\mathrm{Cl}^{-} / \mathrm{H}^{+}$symport, and d) the fatty acid flip-flop mechanism.

The anionic fatty acid headgroup cannot freely diffuse through the lipophilic membrane interior. However, complexation by a transporter allows the carboxylate head group to form a charge-masked complex allowing it to diffuse through the hydrophobic membrane core. ${ }^{16,} 17$ This, combined with the protonation of the headgroup, free diffusion of the neutral species, and eventual deprotonation of the headgroup, completes a proton transport cycle (Figure 2, d), allowing an anion transporter to facilitate $\mathrm{H}^{+}$transport synergistically with a fatty acid. ${ }^{16}$ Anion transporters can also facilitate $\mathrm{H}^{+} / \mathrm{OH}^{-}$transport via fatty acid-independent mechanisms, 
including transporter deprotonation and $\mathrm{OH}^{-}$transport. Hence, a comparison between the two conditions must be made to determine the influence of the fatty acid flip-flop mechanism. The first condition to be tested is vesicles containing fatty acid impurities (Figure 2, a), while the second is where the fatty acids have been sequestered from the membrane (Figure 2, c).

To analyse whether the transporters facilitate $\mathrm{H}^{+}$or $\mathrm{OH}^{-}$transport predominantly via the fatty acid flip-flop mechanism or fatty acid independent mechanisms (e.g., transporter deprotonation or $\mathrm{OH}^{-}$transport), the fatty acids are sequestered from the vesicle membrane by treatment with bovine serum albumin (BSA, Figure 2, c). The removal of the fatty acids embedded in the membrane prevents fatty acid flip-flop assisted $\mathrm{H}^{+}$transport (however, it should be noted that the BSA-fatty acid-binding is a dynamic equilibrium, and the traces of residual free fatty acids after BSA treatment can still contribute to a fatty acid-dependent $\mathrm{H}^{+}$transport pathway). ${ }^{16} \mathrm{~A}$ reduced $\mathrm{pH}$ dissipation rate in the presence of BSA indicates a fatty acid-dependent $\mathrm{H}^{+}$transport mechanism for the anion transporter. However, additional control experiments may be required to rule out BSA-transporter interactions that could also result in reduced transport rates.

Next, transport activity observed when vesicles are treated with the weak acid protonophore carbonyl cyanide- $p$-trifluoromethoxyphenylhydrazone (FCCP) reveals the transporter's ability to perform anion uniport (Figure 2, b). The protonophore facilitates efficient proton transport, which removes the rate-limiting proton transport step. ${ }^{16,} 18$ Although slightly less efficient than FCCP, a similar protonophore, carbonyl cyanide- $m$ chlorophenylhydrazone (CCCP), may be used in place of FCCP as a cheaper alternative. 
Alternatively, the assay can be modified to be much more sensitive by using the proton channel Gramicidin D (Gra), a compound capable of highly efficient proton shuttling. The Gale group have predominantly used Gra instead of FCCP and found Gra to give a greater rate enhancement than FCCP for anion transporters with rate-limiting $\mathrm{H}^{+} / \mathrm{OH}^{-}$transport. However, Gramicidin D is also capable of sodium cation transport, so the $\mathrm{NaX}(100 \mathrm{mM})$ intra- and extravesicular salts must be switched to $N$-methyl-Dglucamine (NMDG) salts. ${ }^{15}$ The highly hydrophilic nature of the $\mathrm{NMDG}^{+}$cation has led to it being used as a common alternative in the HPTS transport assay, as it neither aids nor hinders anion transport due to the inability of Gra to transport the bulky counterion. By adding acid or base containing the anion ' $\mathrm{X}$ ', of interest to calibrate the bulk internal and external solutions containing NMDG $(100 \mathrm{mM})$ to $\mathrm{pH} 7.0$, the NMDG-X salt is formed.

a)

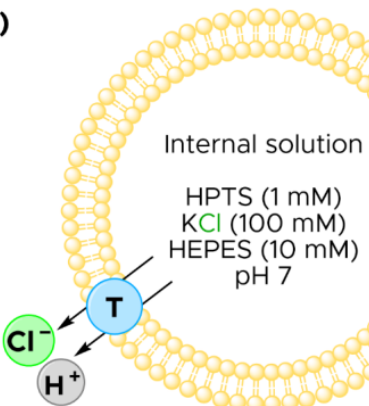

b)

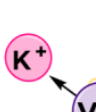

VIn

Internal solution

HPTS (1 mM)

$\mathrm{KCl}(100 \mathrm{mM})$

HEPES $(10 \mathrm{mM})$

$\mathrm{pH} 7$
$\mathrm{pH}$

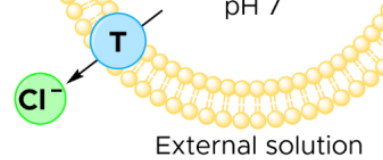

$\mathrm{KCl}(100 \mathrm{mM})$, HEPES (10 mM), pH 8 c)

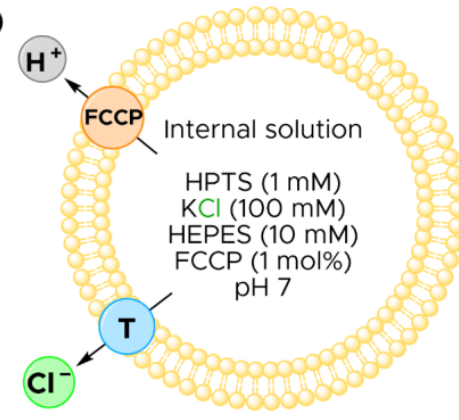

Figure 3. The conditions used to determine a) the transport facilitated when only the synthetic transporter ( $\mathrm{T}$, blue) has been added (control), b) the $\mathrm{H}^{+} / \mathrm{OH}^{-}$selective transport occurring when the potassium $\left(\mathrm{K}^{+}\right.$, pink) ionophore valinomycin (Vln, purple) is added to the system, and c) the transport occurring in the presence of the protonophore FCCP (orange). Note that the internal and external solutions of conditions a) and c) can be either $\mathrm{NaCl}$ (or NMDG-Cl) or $\mathrm{KCl}$. In contrast, an internal and external solution of $\mathrm{KCl}(100 \mathrm{mM})$ is required to test condition $\mathbf{b})$.

Lastly, to determine the $\mathrm{Cl}^{-}$vs $\mathrm{H}^{+} / \mathrm{OH}^{-}$transport selectivity (providing the transporter being tested can facilitate anion-selective transport (uniport)), the HPTS 
assay is conducted with either valinomycin (Vln), a potassium-selective ionophore that transports $\mathrm{K}^{+}$down an electrochemical gradient, or FCCP (CCCP or Gra with NMDG$\mathrm{Cl}$, Figure 3, a, and $\mathbf{b})$. The transport observed in these systems can be compared to a control experiment using only the transporter to facilitate transport (Figure 3, c). It should be noted that several anion transporters have been reported to be inactive in facilitating uniport processes due to strong interactions with the phospholipid headgroup, which inhibits the free transporter diffusion. These anion transporters are unsuitable for these experiments because coupling to either Vln or FCCP (or Gra) requires a uniport mechanism. ${ }^{18}$

Compared to the control experiment, enhanced transport activity seen during the Vln treated experiment indicates $\mathrm{Cl}^{-}<\mathrm{H}^{+} / \mathrm{OH}^{-}$selectivity of the anion transporter as the Vln replaces the rate-limiting $\mathrm{Cl}^{-}$transport step through the rapid transport of the $\mathrm{K}^{+}$ counter cation. ${ }^{18,} 19$ This type of anion transporter does not respond to the proton transporter FCCP (or Gra) because the rate-limiting process, $\mathrm{H}^{+}$transport, is not improved. On the other hand, $\mathrm{Cl}^{-}>\mathrm{H}^{+} / \mathrm{OH}^{-}$anion transporters demonstrate enhanced transport in the presence of protonophore FCCP and insensitivity to Vln. Insensitivity to both FCCP and Vln might indicate a 'non-uniporting' mechanism or similar $\mathrm{H}^{+}$and $\mathrm{Cl}^{-}$ transport rates. ${ }^{18,19}$

\section{Exploring the selectivity among different anions:}

The HPTS assay offers considerable flexibility for comparing the transport activity between different anions $\left(\mathrm{X}^{-}\right.$, as $\left.\mathrm{NaX}\right)$ of interest; chloride can be swapped for ' $\mathrm{X}^{-}$' during the preparation of the internal and external solutions. ${ }^{15,20}$ Care must be taken, however, to avoid misinterpretation of the transport data. A recent study has shown that the misuse of an HPTS selectivity assay that uses NaCl-pH $7.0^{\mathrm{IN}} / \mathrm{NaX}-\mathrm{pH} \quad 8.0^{\text {OUT }}$ conditions has led to many false reports of chloride-selective anion transporters. ${ }^{15}$ This 
assay assumes that anion exchange is much faster than the $\mathrm{pH}$ gradient dissipation. However, some hydrogen-bonding-based transporters can facilitate electroneutral transport that is assisted by (de)protonation via fatty acid headgroup binding or cotransport via the fatty acid flip-flop pathway seen in Figure 2, d, resulting in the $\mathrm{pH}$ dissipation process being faster than anion exchange. ${ }^{1,21} \mathrm{~A}$ less problematic assay based on comparing the rate of $\mathrm{pH}$ gradient dissipation under $\mathrm{NaX}-\mathrm{pH} 7.0^{\mathrm{IN}} / \mathrm{NaX}-\mathrm{pH} 8.0^{\mathrm{OUT}}$ conditions often reveals an incorrect selectivity sequence due to potential aniondependent partitioning of transporters in the membrane.

a)

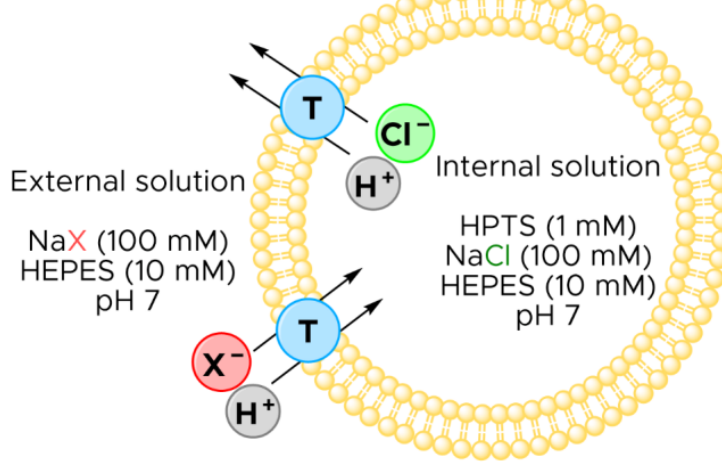

b)

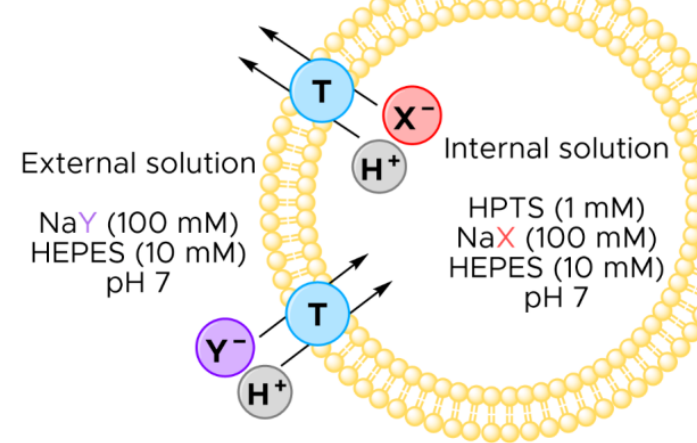

Figure 4. The recommended HPTS selectivity assay a) utilising an 'anion gradient' to analyse the overall anion $\left(\mathrm{X}^{-}\right.$, red) transport selectivity compared with intravesicular $\mathrm{NaCl}$ elicited by a transporter $(\mathrm{T}$, blue) b) the more sensitive derivative of the 'anion gradient' assay known as the 'competitive' assay is used for definitive anion selectivity determination. The internal and external solutions contain the anions of interest, $\mathrm{X}^{-}$ (red, $\mathrm{NaX}$ ) and $\mathrm{Y}^{-}$(purple, $\mathrm{NaY}$ ).

\section{Exploring selective transport:}

To circumvent the abovementioned issues, $\mathrm{Wu}$ and Gale recommended a modified HPTS transport assay (Figure 4, a, termed as the 'anion gradient' assay) for studying anion selectivity by switching the external solution for a solution of the anion of interest ' $\mathrm{X}^{-}$( $\left.\mathrm{NaX}, 100 \mathrm{mM}\right)$ without adding a base pulse. ${ }^{15}$ The driving force of the observed transport is the transporter-induced membrane potential arising from different transport 
rates of $\mathrm{Cl}^{-}$and $\mathrm{X}^{-}$that dictates the direction and magnitude of $\mathrm{H}^{+}$(or $\mathrm{OH}^{-}$) transport. The principle of this assay can be interpreted by comparing the rates of $\mathrm{HCl}$ efflux (or $\mathrm{Cl}^{-} / \mathrm{OH}^{-}$antiport) and $\mathrm{HX}$ influx (or $\mathrm{Cl}^{-} / \mathrm{X}^{-}$antiport). In the case of $\mathrm{HX}$ influx being more efficient than $\mathrm{HCl}$ efflux, the interior of the vesicles is acidified, inferring $\mathrm{X}^{-}>$ $\mathrm{Cl}^{-}$selectivity and membrane permeability of the transporter-anion complex. In contrast, basification of the internal solution due to faster $\mathrm{HCl}$ efflux by anions other than $\mathrm{Cl}^{-}$indicates a higher transporter-facilitated membrane permeability of $\mathrm{Cl}^{-}$over $\mathrm{X}^{-}$. The selectivity between two non-chloride anions $\mathrm{X}^{-}$and $\mathrm{Y}^{-}$can also be determined by comparing the maximum $\Delta \mathrm{pH}_{\mathrm{IN}}$ (maximum intravesicular $\mathrm{pH}$ change in the kinetic plots) values under $\mathrm{NaX}^{\mathrm{IN}} / \mathrm{NaCl}^{\text {OUT }}$ and $\mathrm{NaY}^{\mathrm{IN}} / \mathrm{NaCl}^{\text {OUT }}$ conditions. If the transporter does not facilitate $\mathrm{H}^{+} / \mathrm{OH}^{-}$transport, leading to no activity in the HPTS assay, a proton channel such as FCCP (or CCCP) can be added.

When the anion transport selectivity sequence remains ambiguous after being subjected to the anion gradient assay (e.g., the maximum $\Delta \mathrm{pH}_{\mathrm{IN}}$ values are similar for anions $\mathrm{X}^{-}$and $\mathrm{Y}^{-}$), an adjusted 'anion gradient' assay, also referred to as the 'competitive' assay, has shown to aid in quantitative determination (Figure 4, b). The 'competitive' assay utilises similar conditions to the 'anion gradient' assay; however, a $\mathrm{NaX}^{\mathrm{IN}} / \mathrm{NaY}$ OUT concentration gradient rather than $\mathrm{NaCl}^{\mathrm{IN}} / \mathrm{NaX}{ }^{\mathrm{OUT}}$ is used for a direct and more sensitive comparison between $\mathrm{X}^{-}$and $\mathrm{Y}^{-} \cdot{ }^{15}$ Therefore, a combinational approach using both the 'anion gradient' and the 'competitive' HPTS transport assays is recommended to prevent misinterpretation of data. Herein we report the required equipment, appropriate methodologies and troubleshooting guidance for conducting the HPTS transport assay. 


\section{Materials and Equipment:}

\section{Lipids:}

The choice of lipid is crucial, given that commercially available lipids possess different compositions and properties that can affect transport activity. In this regard, it is advisable to use both the same batch and type of lipid if transport results are to be compared. The chosen lipid should (a) be easy to handle in the laboratory, (b) provide repeatable results, (c) be affordable, (d) be as similar as possible to the biological membranes it mimics (this is especially important when transport assays are performed to explore the activity of novel therapeutic agents). A literature search shows that egg yolk phosphatidylcholine (EYPC) and 2-oleoyl-1-palmitoyl-sn-glycero-3phosphocholine (POPC, Figure 5) are the most commonly used lipids; however, 1palmitoyl-2-oleoyl-sn-glycero-3-phosphoethanolamine (POPE) and 1-palmitoyl-2oleoyl-sn-glycero-3-phosphoglycerol (POPG) have also been employed. For instance, Matile's, ${ }^{22-27}$ Talukdar's, ${ }^{28-32}$ and Ballester's ${ }^{22,} 33$ research groups have used EYPC from Avanti Polar Lipids, while Chen ${ }^{34-38}$ and Manna ${ }^{39,40}$ have also used EYPC but purchased from Sigma-Aldrich. On the other hand, the Gale, ${ }^{15,18,21,41-44}$ and Quesada ${ }^{45}$, 46 research groups have opted to use POPC from Avanti Polar Lipids and SigmaAldrich, respectively, while Poolman ${ }^{47}$ has used mixtures of POPC, POPE and POPG, purchased from Avanti Polar Lipids.

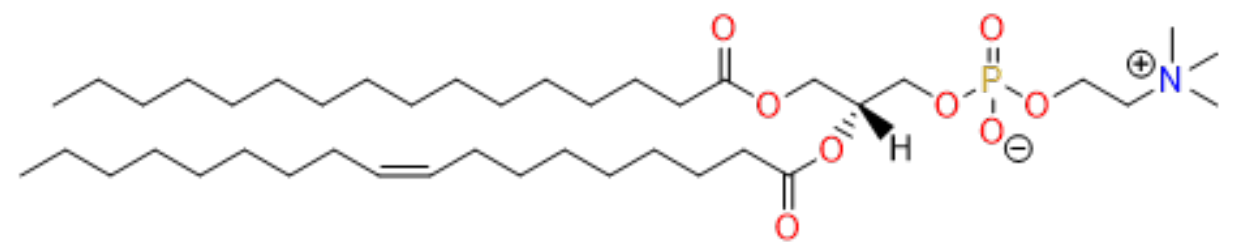

Figure 5. Structure of POPC, a commonly used lipid to perform HPTS-based experiments. 
As indicated before, when it comes to choosing the appropriate lipid to conduct transport assays, the decision should be made by considering, among other factors, the biological membranes to be mimicked. In this respect, EYPC is usually selected because it can emulate mammalian phospholipid composition. EYPC is a natural lipid mixture in which POPC is the main ingredient. ${ }^{48}$ This mixture is made of lipids with various tail lengths and a number of unsaturated bonds, which may result in slightly different compositions and average molecular weights for different batches; however, this disparity between batches depends on the purity of the purchased product. ${ }^{48,}{ }^{49}$ In contradistinction, POPC is a synthetic lipid product with a certified purity, which ensures a higher consistency is maintained between batches and, in turn, affords reliable data. ${ }^{15}$ Like EYPC, POPC also very closely mimics a mammalian phospholipid composition due to the positions of the (un)saturations on the chains while also having a known distribution of fatty acids. However, it should be noted that the free fatty acid content (not the type) may differ depending on the supplier. While this does not affect the chloride/nitrate transmembrane exchange monitored by a chloride-selective electrode, it may have some impact on the results of HPTS-based assays, as fatty acids enhance proton transport across the vesicles' membrane (see the Experiments section). ${ }^{16,21}$ Finally, it is important to note that sometimes a mixture of lipid and cholesterol has been prepared to carry out transport experiments due to the contribution of the latter to the stabilisation of the vesicles' membrane. ${ }^{34,39,40,46}$ Their proportions may vary, but Quesada's group uses a 7:3 POPC:cholesterol mixture with good results.

\section{The salts:}

Transport during HPTS assays is typically initiated with a base pulse, meaning that both the intra- and extravesicular solutions must be buffered to $\mathrm{pH} 7.0$ before the beginning of the experiments. The buffers, the salts employed to prepare these solutions, and the 
base used to induce the $\mathrm{pH}$ gradient should be analytical grade chemicals with high purity, usually higher than $99 \%$.

Although HEPES $(10 \mathrm{mM})$ is the most widely used buffer to carry out this experiment, others, such as the $\mathrm{NaH}_{2} \mathrm{PO}_{4} / \mathrm{Na}_{2} \mathrm{HPO}_{4}(10 \mathrm{mM})$ system, can be used as long as they do not interfere with the assay. The flexibility of the HPTS experiment means that different salts $(\mathrm{MX})$ can be employed to prepare the inner and outer solutions. Usually, both are made up of $\mathrm{NaCl}(100 \mathrm{mM})$, but it is not uncommon to find works in the literature where $\mathrm{M}$ is $\mathrm{Li}^{+}, \mathrm{Na}^{+}, \mathrm{K}^{+}, \mathrm{Rb}^{+}, \mathrm{Cs}^{+}$or $\mathrm{NMDG}^{+}$and $\mathrm{X}$ is $\mathrm{F}^{-}, \mathrm{Cl}^{-}$, $\mathrm{Br}^{-}, \mathrm{I}^{-}, \mathrm{NO}_{3}{ }^{-}, \mathrm{AcO}^{-}, \mathrm{SCN}^{-}$or $\mathrm{ClO}_{4}{ }^{-} \cdot{ }^{15}, 31,43,45$ The intra- and extravesicular media composition may be dissimilar depending on the purpose of the experiment $(\mathrm{pH}$, anion or dual gradient assay); however, regardless of the composition, the total ionic strength of both solutions must remain constant throughout a typical experiment.

\section{HPTS:}

HPTS is a non-toxic, water-soluble fluorescent pyrene derivative bearing three sulfonate groups at positions 1, 3, and 6 and a hydroxyl group at position 8 (Figure 6). HPTS has been employed as a dye and chemosensor, ${ }^{50}$ as a tool to develop environmental sensors, ${ }^{51,52}$ to monitor protein structural transitions, ${ }^{53-55}$ and as a fluorometric $\mathrm{pH}$ indicator. HPTS is sensitive to $\mathrm{pH}$ changes from the protonation/deprotonation of the hydroxyl group and has a $\mathrm{p} K_{\mathrm{a}}$ of $\sim 7.3$ (although this depends on the experimental conditions and will be discussed in the calibration section). ${ }^{56}$ This $\mathrm{p} K_{\mathrm{a}}$ value is close to physiological $\mathrm{pH}$, making HPTS an ideal candidate to monitor $\mathrm{pH}$ variations in biological media. HPTS has been used to measure intracellular $\mathrm{pH}$ and, as indicated above, intravesicular $\mathrm{pH}^{57,}{ }^{58}$ Absorption wavelengths of the protonated and deprotonated forms of this probe are different, but they both emit at $510 \mathrm{~nm}$. If the sample is excited at $460 \mathrm{~nm}$ (the excitation wavelength of the deprotonated form) and at 
$403 \mathrm{~nm}$ (the protonated form), and the emission intensity at $510 \mathrm{~nm}$ recorded for both excitations, it is possible to determine the $I_{460} / I_{403}$ ratio (Figure 6, Equation (1)). Also, if there is a variation of the $I_{460} / I_{403}$ quotient occurring with time, it means that the intravesicular $\mathrm{pH}$ is also changing; if it remains constant, the inner $\mathrm{pH}$ is not disturbed. Therefore, the HPTS assay is an example of ratiometric $\mathrm{pH}$ monitoring based on the emission properties of the probe. Ratiometric monitoring with a single probe is not a common feature since such tracking usually requires combining two different fluorescent dyes, one of them sensitive to $\mathrm{pH}$ changes and the other insensitive. ${ }^{59}$ Consequently, this reduces errors related to probe concentration, photobleaching, and instrumentation. ${ }^{60}$

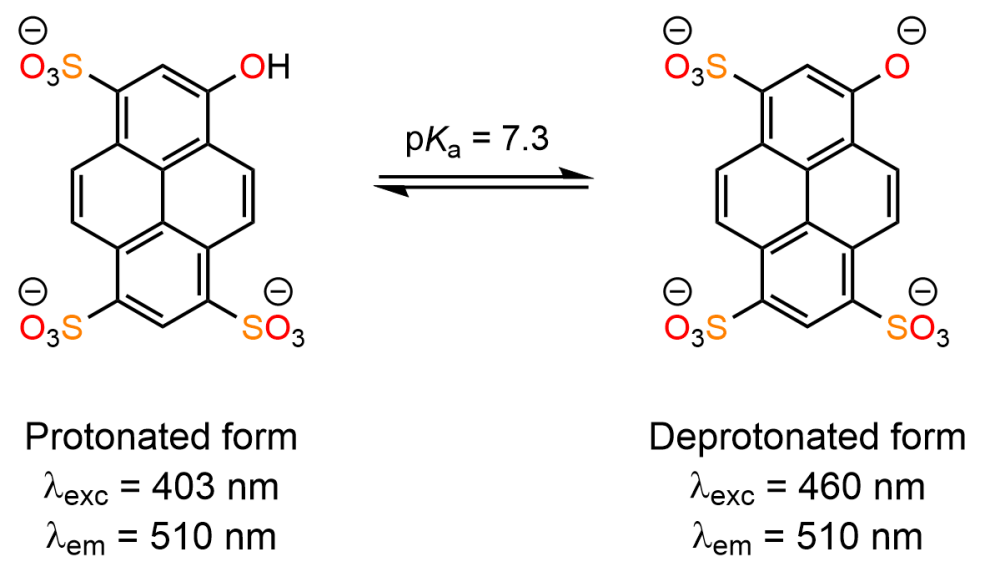

Figure 6. The protonated and deprotonated forms of HPTS with their excitation and emission wavelengths.

$$
\frac{I_{e m}, 510 \mathrm{~nm}(\text { exc. at } 460 \mathrm{~nm})}{I_{e m}, 510 \mathrm{~nm}(\text { exc. at } 403 \mathrm{~nm})}=\frac{I_{460}}{I_{403}}
$$

Once the $I_{460} / I_{403}$ values at different times have been collected (a typical transport experiment with HPTS-containing vesicles lasts $6 \mathrm{~min}$ ), they can be converted to fractional fluorescence values $\left(I_{\mathrm{f}}\right)$ using Equation (2): 


$$
I_{f}=\frac{R_{t}-R_{0}}{R_{f}-R_{0}}
$$

where; $R_{t}$ is the fluorescence ratio at time $t, R_{0}$ is the fluorescence ratio at time $t=0$, and $R_{f}$ is the final fluorescence ratio (after lysing the vesicles exposing $100 \%$ of the encapsulated HPTS) obtained by curve fitting to the single exponential decay function. Also, to ensure the precise determination of the $R_{f}$ value, the assay can be run for as long as necessary after lysing the vesicles so an accurate final fluorescence ratio can be recorded to normalise the data. ${ }^{15}$ On the other hand, fluorescence ratios can be turned into $\mathrm{pH}$ values. In order to perform this conversion, it is necessary to ascertain the mathematical relationship between $I_{460} / I_{403}$ and $\mathrm{pH}$. This process is called 'calibration' and can be conducted in two different ways: (a) with or (b) without vesicles. In the case of (a), vesicles are loaded with a buffered aqueous solution containing $\mathrm{NaX}$ and HPTS and suspended in HPTS-free solutions adjusted to different $\mathrm{pH}$ values with $\mathrm{NaOH}$. The inner $\mathrm{pH}\left(\mathrm{pH}_{\mathrm{IN}}\right)$ is equilibrated to the outer $\mathrm{pH}\left(\mathrm{pH}_{\mathrm{OUT}}\right)$ by adding monensin, a sodium cationophore (see the HPTS Transport Assay Experimental and Preparatory Procedures section for further experimental details).

Regarding (b), aliquots of $\mathrm{NaOH}$ are successively added to a NaX- and HPTScontaining buffered aqueous solution (see the HPTS Transport Assay Experimental and Preparatory Procedures section for further experimental details). Upon equilibration of $\mathrm{pH}_{\mathrm{IN}}$ and $\mathrm{pH}_{\mathrm{OUT}}$, in the case of (a), or after each addition of the sodium hydroxide solution, in the case of (b), fluorescence ratios are recorded and plotted as a function of $\mathrm{pH}$, or vice versa, and the resulting curve is fitted to a certain model (Figure 7). For $\mathrm{pH}$ vs $I_{460} / I_{403}$ representations, a modified equation derived from the Henderson-Hasselbach equation is commonly used (Equation (3)):

$$
y=\log \frac{a x-b}{c-x}
$$




$$
y=\frac{a}{\left(1+e^{-k \cdot(x-x c)}\right)}
$$

where; $x=I_{460} / I_{403}$ and $y=\mathrm{pH}$, and $a, b$, and $c$ are model-derived calibration constants. If $I_{460} / I_{403}$ is plotted against $\mathrm{pH}$, the Slogisticl model available at OriginPro ${ }^{\circledR}$ (Equation (4)) is frequently employed; in this case, $x=\mathrm{pH}$ and $y=I_{460} / I_{403}$, and $a, c$, and $k$ are model-derived calibration constants. Calibration is a critical step in this process and must be conducted carefully. It is highly advisable to perform it in conditions that mimic, as much as possible, those of the transport experiments to obtain reliable results. In the case of (b), i.e., calibration in the absence of vesicles, we have noticed that depending on the salt $(\mathrm{NaX})$ employed, the ionic strength of the solution, and the HPTS concentration, the $\mathrm{p} K_{\mathrm{a}}$ of the fluorophore changes, meaning that the calibration equation is modified. Temperature is also a crucial variable. All these factors must be controlled to avoid inconsistencies between raw data provided by the spectrofluorometer, and $\mathrm{pH}$ values, resulting from applying the calibration equation.
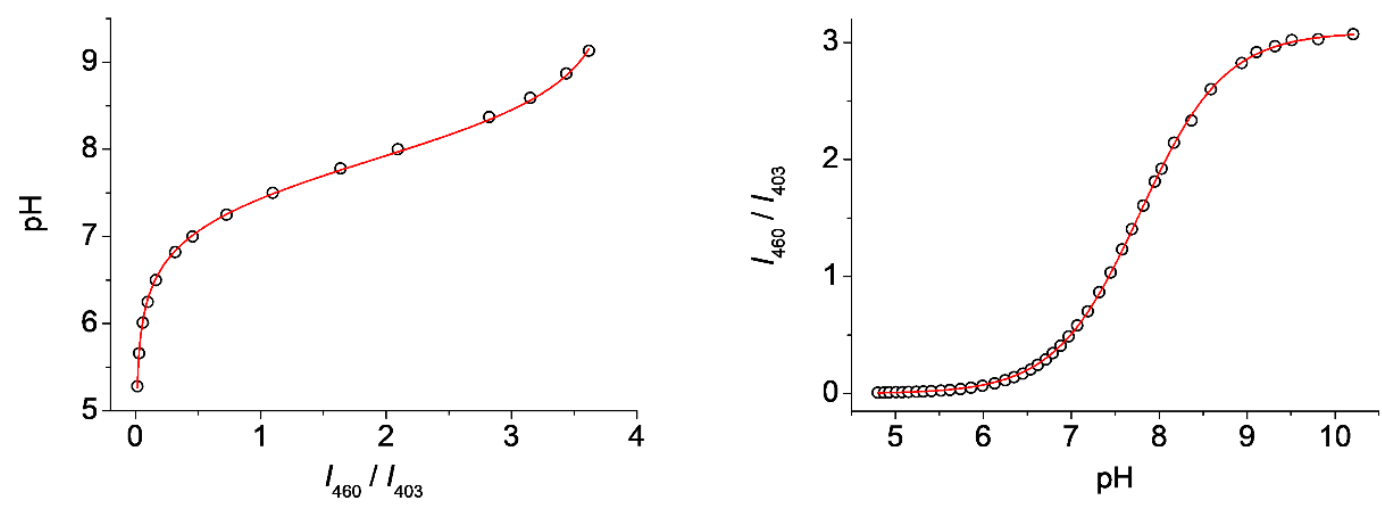

\begin{tabular}{|c|c|c|c|}
\hline Model & \multicolumn{3}{|c|}{ HPTS Calibration } \\
\hline Equation & \multicolumn{3}{|c|}{$y=\log ((a \cdot x-b) \div(c-x))$} \\
\hline Reduced Chi-Sqr & \multicolumn{3}{|c|}{$5.8736 \mathrm{E}-4$} \\
\hline Adj. R-Square & & 0.99959 \\
\hline & Constants & Value & Standard Error \\
\hline \multirow{2}{*}{ D } & $a$ & $7.70611 \mathrm{E} 7$ & $1.56787 \mathrm{E} 6$ \\
\cline { 2 - 4 } & $b$ & 540696.05663 & 46624.73931 \\
\cline { 2 - 4 } & $c$ & 3.81246 & 0.012 \\
\hline
\end{tabular}

\begin{tabular}{|c|c|c|c|}
\hline Model & \multicolumn{3}{|c|}{ Slogistic1 } \\
\hline Equation & \multicolumn{3}{|c|}{$y=a \div(1+\exp (-k \cdot(x-x c)))$} \\
\hline Reduced Chi-Sqr & \multicolumn{3}{|c|}{$1.26344 \mathrm{E}-4$} \\
\hline Adj. R-Square & & 0.9999 \\
\hline & Constants & Value & Standard Error \\
\hline \multirow{2}{*}{ B } & $a$ & 3.08792 & 0.00598 \\
\cline { 2 - 4 } & $x C$ & 7.78319 & 0.00349 \\
\cline { 2 - 4 } & $k$ & 2.07289 & 0.0111 \\
\hline
\end{tabular}

Figure 7. Curves obtained after performing calibration with (left) or without (right) vesicles, fitted to Equations (3) and (4), respectively. ${ }^{15}$ 


\section{Other things to think about:}

Besides the equipment and materials described in previous sections, there are some other items that are essential to perform HPTS-based transport experiments. An analytical balance is required to weigh the lipids, and the salts used to prepare the aqueous solutions of; sodium hydroxide, HEPES, and HPTS. Equipment such as a rotary evaporator and a high vacuum pump is needed to dry the lipid and ensure the formation of a smooth film. When preparing the buffered solutions, access to Type 1 (Milli-Q) water is mandatory to avoid ion contamination. A pH meter must be used to adjust these solutions to the desired $\mathrm{pH}$ value. A dispersion of Triton $\mathrm{X}-100$ in water $(10 \% v / v)$ is required to lyse the vesicles and obtain a value for equilibrium $\mathrm{pH}$. Volumetric flasks, a vortex mixer, liquid nitrogen (or, if not available, a dry ice-acetone bath), an extrusion kit equipped with $200 \mathrm{~nm}$ polycarbonate membranes, and a chromatography column loaded with hydrated G-25 Sephadex ${ }^{\circledR}$ are key to preparing the vesicles. Micropipettes with tips, disposable cuvettes, micro-PTFE stirrer bars (approx. $8 \mathrm{~mm}$ ), and a stopwatch are also required to perform these experiments. 


\section{HPTS Transport Assay Experimental and Preparatory Procedures:}

To better conceptualise how to prepare for and run an HPTS transport experiment, a flowchart (Scheme 1) has been included, visualising the order that each preparation and experimental step should be completed for a successful experiment.

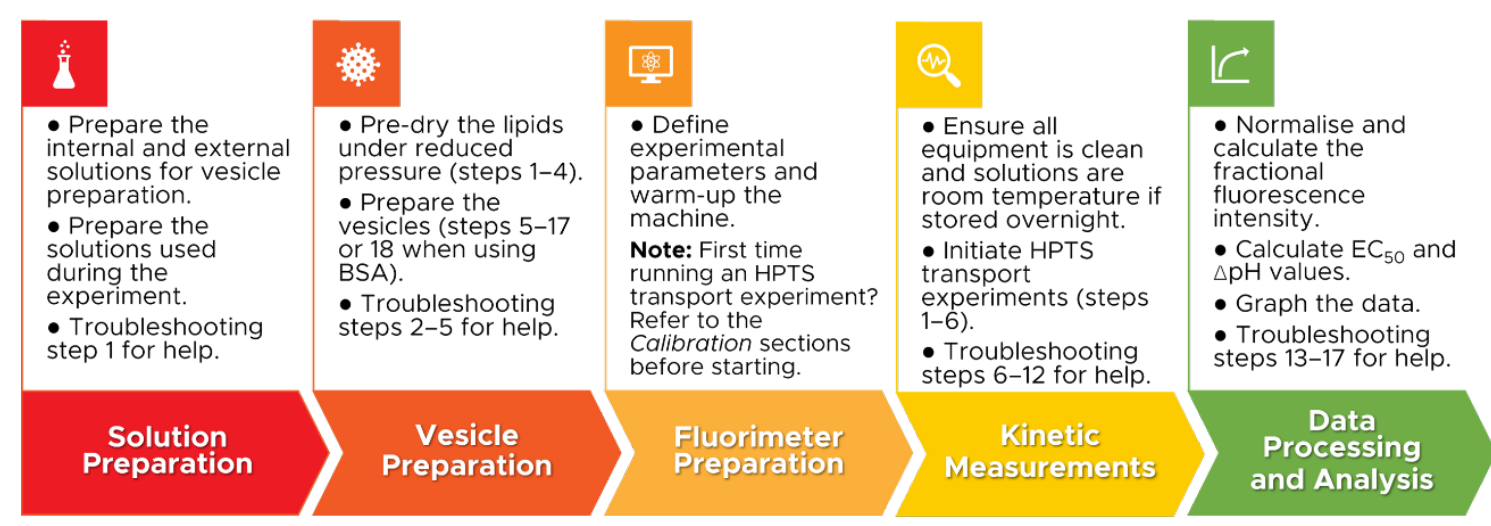

Scheme 1. A flowchart describing the stepwise procedures which are required to prepare for and carry out an HPTS transport assay.

\section{Preparation of the required solutions:}

(1) A DMSO stock solution of the transporter (5-50 mM), depending on the potency of the transporter, for serial dilutions.

(2) $\mathrm{A} \mathrm{NaCl}(100 \mathrm{mM})$ external solution at $\mathrm{pH} 7.0$, buffered with HEPES (10 mM).

(3) A DMSO solution of the ionophore (Gra, FCCP or CCCP) for the ionophorecoupled experiments ( $1 \mathrm{~mol} \%$ for FCCP and CCCP, or $0.1 \mathrm{~mol} \%$ for Gra).

(4) For ionophore-coupled experiments, the external solution should be made with either $\mathrm{NaCl}$ or $\mathrm{KCl}(100 \mathrm{mM})$; however, if the ionophore used is Gra instead of FCCP (or CCCP), then the external solution should be made of NMDG-Cl or $\mathrm{KCl}(100 \mathrm{mM})$.

(5) An internal solution containing HPTS $(1.05 \mathrm{mg}, 2.0024 \mu \mathrm{mol})$ is prepared from the external solution $(2.0 \mathrm{~mL})$. The HPTS internal solution will be bright green. 
(6) A base pulse solution of $\mathrm{NaOH}(0.5 \mathrm{M})$ for experiments with FCCP (or CCCP) or NMDG-OH (0.5 M) for experiments using Gra in Milli-Q water.

\section{Vesicle preparation:}

(1) Dissolve POPC (1 g) into chloroform (35 mL) to form a solution of POPC lipids $(37.5 \mathrm{mM})$.

(2) Weigh and record the mass of an empty round-bottom flask, then add the POPC chloroform solution $(0.5-4 \mathrm{~mL})$ with a volumetric pipette. Record the volume added for use in step 6. Note: $2 \mathrm{~mL}$ of lipids will last for approx. 200 experiment runs and $10-25 \mathrm{~mL}$ round-bottom flasks are commonly used depending on lipid solution volume.

(3) Remove the chloroform on a rotary evaporator, equipped with a water bath, under vacuum to give a uniform lipid surface. We recommend setting the bath to $40{ }^{\circ} \mathrm{C}(313.15 \mathrm{~K})$ and rotation speed to $200 \mathrm{rpm}$ for the best results. Evaporation pressure begins with $150 \mathrm{mbar}(15 \mathrm{kPa})$ for $1 \mathrm{~min}$, followed by $2 \mathrm{~min}$ at 100 mbar $(10 \mathrm{kPa})$, and finally $5 \mathrm{~min}$ at $50 \mathrm{mbar}(5 \mathrm{kPa})$ (Figure 8).

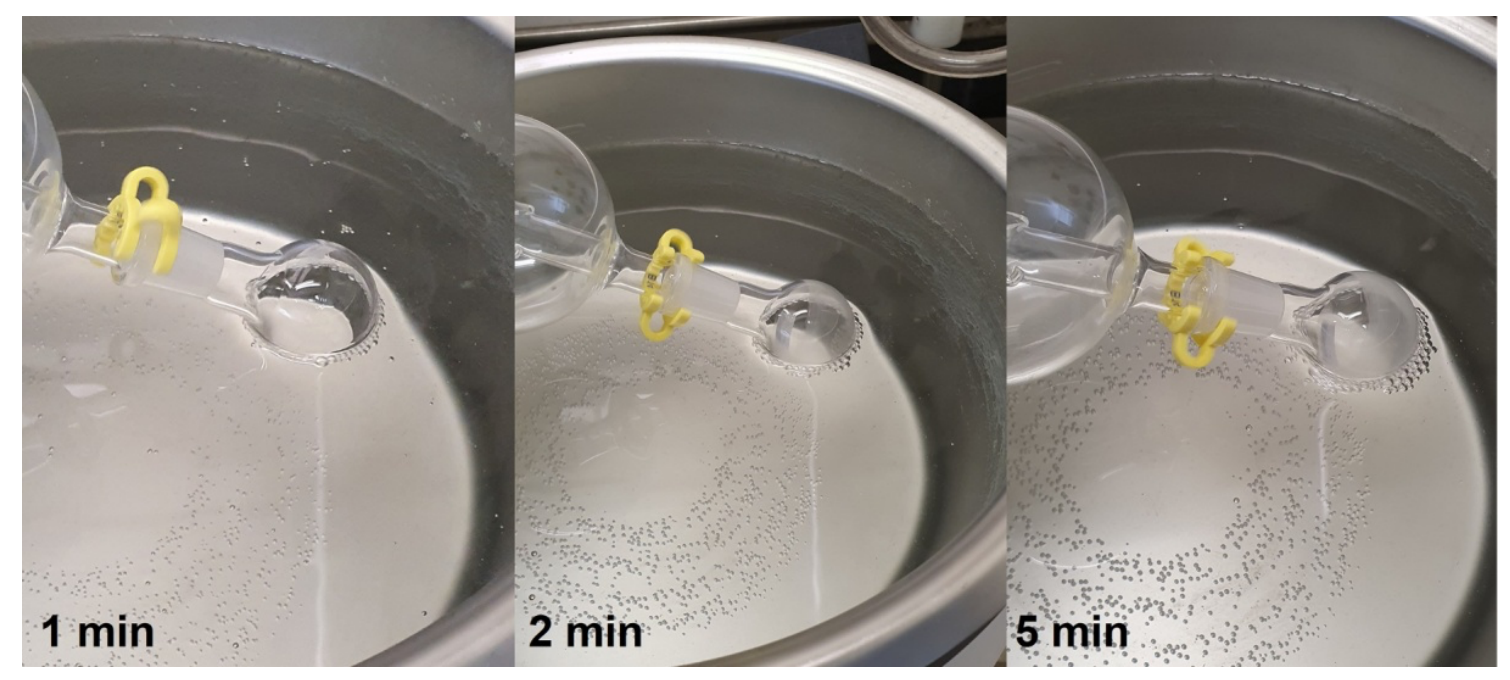

Figure 8. The progressive stages of the lipid film when drying under reduced pressure. 
(4) Dry the lipid film in a vacuum desiccator for a minimum of $6 \mathrm{~h}$, preferably overnight. Note: In this example, we have used a VACUUBRANDTM RZ 6 Rotary Vane Pump, a vacuum of $2.7 \times 10^{-4}$ or $2.0 \times 10^{-4} \mathrm{kPa}$ was applied to a vacuum desiccator with or without using the gas ballast, respectively.

(5) Weigh the round-bottom flask again with the dried lipids and calculate the mass of the lipid film. This step is essential to calculate the concentration of the final vesicle solution.

(6) Use an autopipette to add the same volume of HPTS internal solution as recorded in step 2 to the round-bottom flask containing the dried lipid film.

(7) Re-hydrate the lipids by vortexing until there are no more lipids stuck on the interior surface of the flask (Figure 9, a).

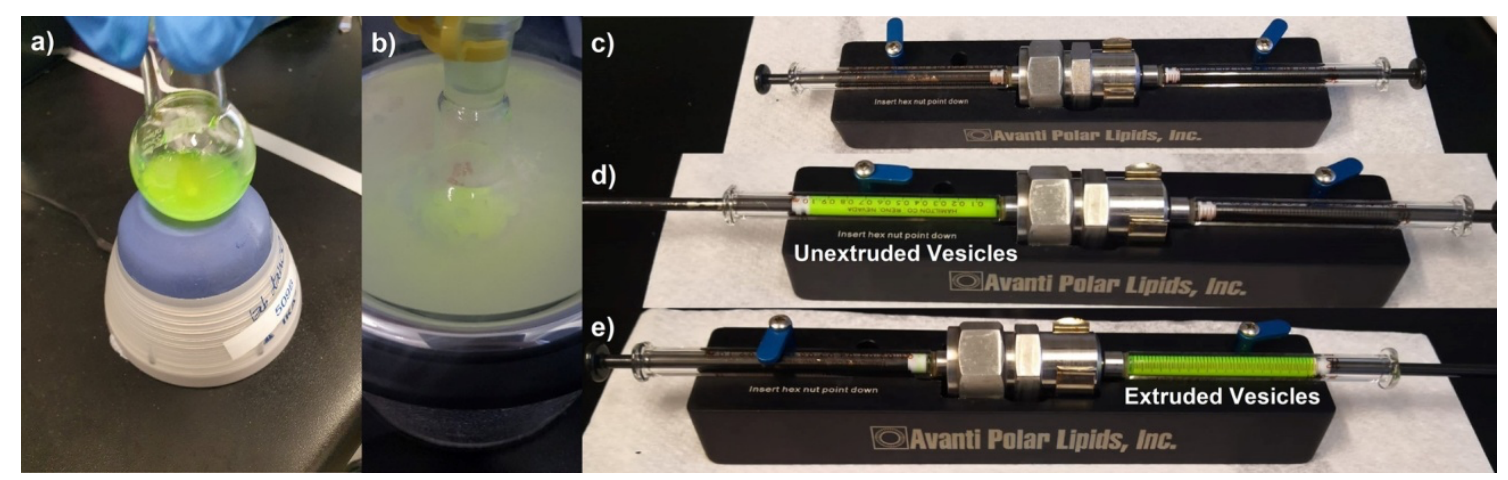

Figure 9. a) The dried lipids were re-hydrated with the internal solution before undergoing b) nine freeze-thaw cycles with liquid nitrogen and lukewarm water. The now unilamellar vesicles were c) extruded through a $200 \mathrm{~nm}$ polycarbonate membrane using the Avanti Polar Lipids, Inc extrusion kit. d) Care was taken only to insert the syringe containing the unextruded lipids into one side, while e) the extruded vesicles were only collected from the other side of the polycarbonate membrane.

(8) Completely freeze the lipids in liquid nitrogen while gently swirling the roundbottom flask (gently invert to check the solution is completely frozen), then thaw in warm water. Repeat this freeze-thaw cycle nine times (Figure 9, b). Safety 
note: dry the outside of the flask of water before re-freezing in liquid nitrogen. The freeze-thaw cycles can also be completed using a dry ice/acetone bath if liquid nitrogen is unavailable.

(9) Set up the Avanti Polar Lipids, Inc extrusion kit with a $200 \mathrm{~nm}$ polycarbonate membrane between two support membranes. Ensure all membranes have been wetted with type 1 Milli-Q water before assembling, that the hex nut apex points downwards, and that all components are assembled tightly. This ensures full insertion to reduce undue pressure on the syringes and mitigates the chance of leakages (Figure 9, c). ${ }^{61}$

(10) Fill one syringe with $1 \mathrm{~mL}$ of the lipid solution and align the tip with one side of the extrusion kit (Figure 9, d). Place the other empty syringe into the opposite side of the kit, ensuring both syringes have tightened tips to minimise leakage.

(11) Extrude the lipid solution through the membrane back and forth 25 times before placing the extruded lipids into a clean vial (Figure 9, e). Record the volume of extruded lipids, as this will be used later. Repeat steps 10 and 11, combining all extruded lipids. Note: only collect the extruded lipids from the syringe that was not initially filled with the unextruded lipid solution to avoid crosscontamination. Clean the extrusion kit thoroughly with Milli-Q water after use.

(12) Set up a B19 size exclusion column. Hydrate the G-25 Sephadex ${ }^{\circledR}$ beads (approx. $2.0 \mathrm{~g}$ ) in Milli-Q water $(100 \mathrm{~mL})$, with gentle stirring, over $2 \mathrm{~h}$ before packing into the column. Allow the beads to settle, ensuring there are no air bubbles dispersed throughout the column. The beads can be reused multiple times before replacing. 
(13) Pre-rinse the column by eluting two column volumes (CV) with the external solution, then load the extruded lipids into the column, being careful not to disturb the Sephadex ${ }^{\circledR}($ Figure 10, a).

(14) Elute the lipids with the external solution, ensuring the column does not run dry. There will be a noticeable separation of a fast-moving pale band (the lipids) and a slow-moving green band (unencapsulated HPTS solution) (Figure 10, b). Collect the pale band minimising the amount of eluent collected before and after (Figure 10, c).

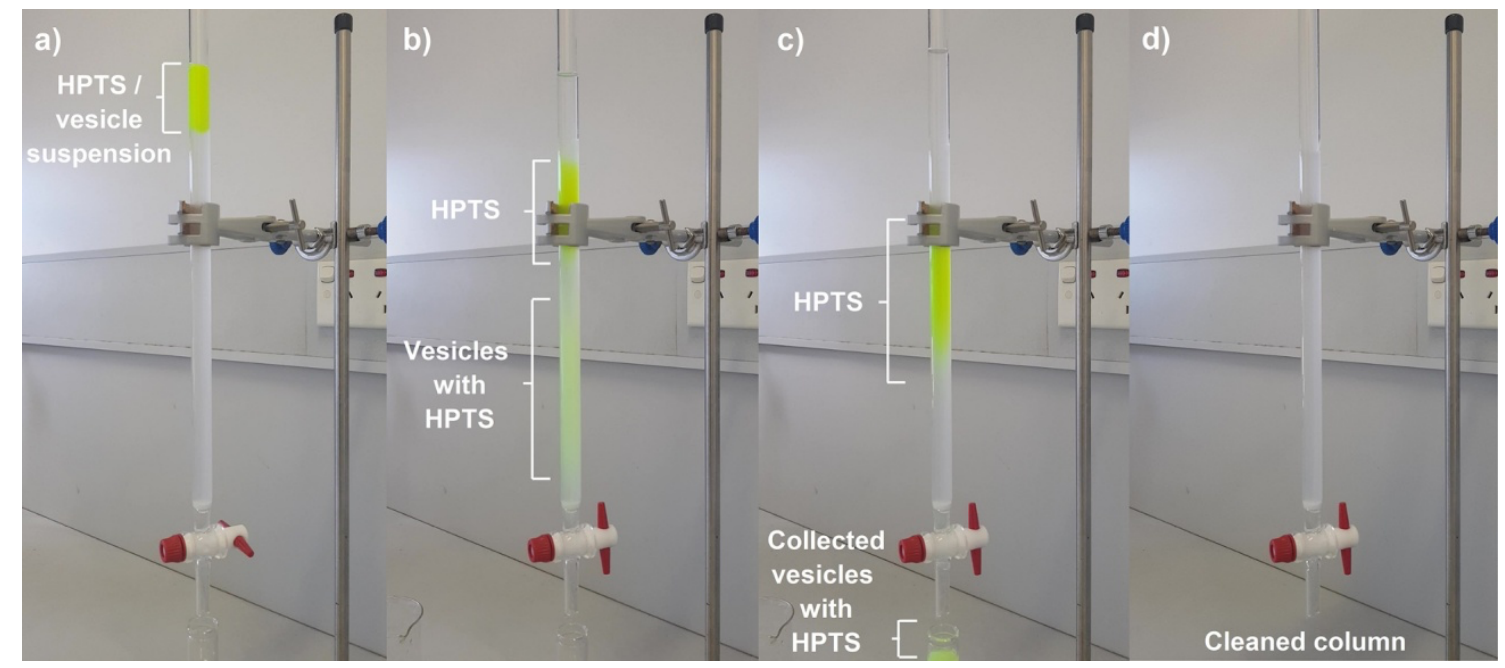

Figure 10. a) The extruded HPTS/vesicle suspension was loaded into the B19 G-25 Sephadex ${ }^{\circledR}$ column. b) Using the external solution as the eluent, the unencapsulated HPTS (the bright green band at the top) and the vesicles (the pale green band near the bottom) were separated. c) The pale green band was collected, and the unencapsulated HPTS was d) eluted with Milli-Q water (three CVs).

(15) Clean the column by eluting with three CVs of Milli-Q water. The column can be reused for future separations. A stopper can also be used to minimise dust entering the column during extended periods between uses (Figure 10, d).

(16) Transfer the lipids to a $10 \mathrm{~mL}$ volumetric flask and top up with the external solution before transferring to a fresh vial. 
(17) Calculate the concentration of lipids in the vial using the method below:

$$
\text { Mass of lipids }(\mathrm{g})=\text { Mass }(\mathrm{g}) \text { from step } 5 \text { - Mass }(\mathrm{g}) \text { from step } 2
$$

$$
\text { Moles of lipids }(\mathrm{mol})=\left(\frac{\text { Mass of lipids }(\mathrm{g})}{\text { Molecular weight of lipid }\left(\mathrm{gmol}^{-1}\right)}\right)
$$

Extruded lipids $(\mathrm{mol})=$ Moles of lipids $(\mathrm{mol}) \times\left(\frac{\text { Lipid vol. }(\mathrm{mL}) \text { in step } 2}{\text { Extruded lipid vol. }(\mathrm{mL})}\right)$

$$
\text { Extruded lipid conc. }(\mathrm{M})=\left(\frac{\text { Extruded lipids }(\mathrm{mol})}{\text { Volumetric flask vol. }(0.010 \mathrm{~L})}\right)
$$

Lipid vol. per run $(\mathrm{mL})=1000 \times\left(\frac{\text { Desired lipid conc. }(0.0001 \mathrm{M}) \times \text { Final vol. }(0.0025 \mathrm{~L})}{\text { Extruded lipid conc. }(\mathrm{M})}\right)(9)$

(18) For BSA-treated experiments, the vesicles must be incubated with BSA ( 1 mol\% with respect to the lipid concentration) for $20 \mathrm{~min}$ before use. Due to the destabilisation of the membrane from the adsorption of BSA and the sequestration of free fatty acids, consideration must be given to the amount of lipids that should be treated since leaking will occur overnight. ${ }^{62}$ Therefore, we recommend that the volume of lipids to be treated does not exceed the number of experiments that can be conducted in a single day. If more BSA experiments need to be performed, treat more of the stored lipid stock.

(19) Note: If desired, dynamic light scattering (DLS) can be used as a means to measure liposome size and polydispersity after preparation. 


\section{The fluorimeter:}

Fluorescence emission spectroscopy exploits the physical phenomenon of excited-state energy emission and is widely used in many fields due to its low detection limit. This technique allows the presence of species at very low concentrations to be determined in several media types. Such species must emit light at a certain wavelength, which a spectrofluorometer can then record. If the species to be investigated are not fluorescent, a fluorophore, such as HPTS, can be used to detect their presence in solution or monitor certain processes triggered by them. Although the Gale and Quesada research groups use different fluorescence spectrophotometers: an Agilent Cary Eclipse, a HORIBA Scientific Fluoromax 4, and a Hitachi F-7000, any spectrofluorometer may work as long as it can detect the fluorescence at the wavelength of interest $(510 \mathrm{~nm})$. However, to ensure consistency, the fluorometer must be equipped with a cell holder with a magnetic stirrer function, a temperature controller, and connected to a computer. Also, to ensure the homogenous distribution of vesicles in solution, a moderate stirring rate should be maintained during the experiments and conducted at a consistent temperature (usually $\left.25{ }^{\circ} \mathrm{C}(298 \mathrm{~K})\right)$. In this way, the obtained data will be comparable. Like any instrument, fluorescence spectrophotometers require maintenance and must be kept clean (especially the cell or multi-cell holder) to avoid dust accumulation and subsequent interference. The lamps should also be changed when reaching the limit of their lifetime (the equipment's software usually informs the user through an alert when the time has come; otherwise, please refer to the manual of the lamp's supplier).

Although the parameters to be set before conducting the assays are common to most instruments, it is advisable to consult the manufacturer's manual in advance since depending on the spectrofluorometer, they may vary. With some equipment, it is possible to obtain the $I_{460} / I_{403}$ ratio value after each measurement, but it might be 
necessary to calculate it manually in other cases. This value comes from the emission intensity detected by the instrument at $510 \mathrm{~nm}$ when the spectrometer rapidly sweeps (within $300 \mathrm{~ms}$ ) between the two excitation wavelengths, 460 and $403 \mathrm{~nm}$ (Figure 6). Therefore, these three wavelengths must be fixed in the instrument's software. The excitation and emission slits must also be set. Depending on the machine and the lipid concentration, the instrument needs to be tuned to the optimal slit width to obtain the best signal to noise $(\mathrm{S} / \mathrm{N})$ ratio. Getting the highest possible fluorescence intensity is desirable to ensure high-resolution data is collected, but this intensity must not overshoot the maximum intensity the machine can record. Once these parameters (and others, depending on the machine) have been saved as 'the method' used to run an experiment, and the instrument was warmed up (the time required for a spectrofluorometer to warm-up is specific to the machine), the transport assays can be carried out. As mentioned above, a typical vesicle-based transport experiment lasts 6 min. Over the course of an experiment, the $I_{460} / I_{403}$ values are recorded every $10 \mathrm{~s}$ automatically or manually, in which case a stopwatch is required. At the end of the assay, detergent is added to lyse the vesicles to ascertain the final $I_{460} / I_{403}$ value and the equilibrium $\mathrm{pH}$. After saving the data, fluorescence ratios $\left(I_{460} / I_{403}\right)$, fractional fluorescence values $\left(I_{\mathrm{f}}\right)$, or $\mathrm{pH}$ can be plotted against time (see the Data treatment section).

\section{Kinetic measurements:}

During the experiment, it would be beneficial to have the transporter dissolved in DMSO at a sufficiently high concentration to make serial dilutions from this stock solution. Note: while HPTS is stable in ambient light, solutions containing iodide or very light-sensitive compounds should be protected by wrapping the storage container in aluminium foil. Under ambient conditions, iodide can be oxidised to iodine, which 
can function as an anion transporter causing undesirable non-transporter related anion transport to occur, skewing results.

(1) To begin the experiment, add the calculated volume of lipids into a cuvette equipped with a micro stirrer bar.

(2) Top up the cuvette to a final volume of $2.5 \mathrm{~mL}$ with the external solution.

(3) Add the $\mathrm{NaOH}$ base pulse solution $(25 \mu \mathrm{L}, 0.5 \mathrm{M})$.

(4) Add the transporter solution $(5 \mu \mathrm{L})$ to begin the experiment.

(5) Allow the experiment to run for a minimum of $200 \mathrm{~s}$ before lysing the vesicles.

(6) To end the experiment, add the Triton $\mathrm{X}-100$ in water dispersion $(50 \mu \mathrm{L}, 10 \%$ $v / v)$ and then collect data for a minimum of $30 \mathrm{~s}$ before stopping data collection.

When performing the ionophore-coupled experiment, add the ionophore solution (5 $\mu \mathrm{L}$ ) before starting the experiment (between steps 2 and 3). When performing experiments on the BSA treated system, make sure to swap the non-treated vesicles for vesicles that have been incubated with BSA while keeping the rest of the procedure the same.

Calibration (without vesicles):

(1) Prepare $50 \mathrm{~mL}$ of the buffered internal solution (remember: it should mimic the conditions of the vesicles inner medium) without adjusting its $\mathrm{pH}$ (the solution should be slightly acidic).

(2) Using the internal solution as a solvent, prepare a solution of HPTS (1 mM) and, from this, a diluted solution of the fluorophore $(10 \mathrm{~mL}, 15 \mathrm{nM})$.

(3) Prepare a $\mathrm{NaOH}$ solution $(10 \mathrm{~mL}, 0.5 \mathrm{M})$ using the internal solution as a solvent.

(4) Transfer the HPTS solution to a vial, ensuring that the $\mathrm{pH}$ meter electrode can fit into it. 
(5) Stir the HPTS solution at a moderate speed and measure and record its $\mathrm{pH}$ value; make sure to maintain constant stirring during the whole calibration.

(6) Take an aliquot $(2.5-3 \mathrm{~mL})$, transfer it to a cuvette, and record the $I_{460} / I_{403}$ ratio (the optimal slit widths depend on the machine; see The fluorimeter section).

(7) Return this solution to the vial, add an aliquot of the $\mathrm{NaOH}$ solution (it should cause an increase of $0.05-0.1 \mathrm{pH}$ units) and record the $\mathrm{pH}$ when it has stabilised.

(8) Follow the procedure indicated in step 6, and after returning the solution to the vial, rinse the cuvette with that solution several times. When close to $\mathrm{pH} \mathrm{7.2,}$ care should be taken, as even small $\mathrm{pH}$ increases can provoke significant changes in the $I_{460} / I_{403}$ ratio.

(9) Keep measuring $\mathrm{pH}$ and recording $I_{460} / I_{403}$ values until the spectrofluorometer provides stable readings.

(10) The recorded $\mathrm{pH}$ values for each $I_{460} / I_{403}$ ratio can be plotted and fitted to Equations (3) or (4).

\section{Calibration (with vesicles):}

The assay should be calibrated with the same vesicles tested in the HPTS assay if the option is available. The procedure for preparation of the standard vesicles has been used in and adapted from the journal article 'Measuring anion transport selectivity: a cautionary tale' by Xin Wu and Philip A. Gale. ${ }^{15}$

(1) Prepare an external solution of $\mathrm{NaCl}(100 \mathrm{mM})$ and HEPES $(10 \mathrm{mM})$ as well as a $\mathrm{NaOH}$ base pulse solution $(0.5 \mathrm{M})$ using Milli-Q water.

(2) Following the general procedure described above (see the Vesicle preparation section), vesicles containing an internal solution of $\mathrm{NaCl}(100 \mathrm{mM})$ and HEPES (10 $\mathrm{mM}$, using the uncalibrated external solution at $\mathrm{pH} 5.3$ ) were made. 
(3) A solution of the prepared vesicles was diluted in a cuvette with the external solution to $2.5 \mathrm{~mL}$ (considering the volume of vesicles added) to afford a lipid concentration of $0.1 \mathrm{mM}$.

(4) An aliquot of monensin, a cationophore, in DMSO $(2.5 \mu \mathrm{L}, 0.5 \mathrm{mM})$ was added to equilibrate the $\mathrm{pH}$ between the internal $\left(\mathrm{pH}_{\mathrm{IN}}\right)$ and external ( $\mathrm{pH}$ OUT $)$ solutions.

(5) The changing fluorescent response of the encapsulated HPTS at the initial $\mathrm{pH}$ of 5.3 was incrementally adjusted to the final $\mathrm{pH}$ of 9.2 with the $\mathrm{NaOH}$ solution $(0.5 \mathrm{M})$ while stirring. The response was recorded using a spectrophotometer.

(6) The data recorded during the HPTS assay, and subsequently by HPTS calibration, is a ratiometric value $\left(I_{460} / I_{403}\right)$ of the fluorescent emission $\left(\lambda_{\mathrm{em}}=\right.$ $510 \mathrm{~nm})$ from both the basic $\left(I_{460}, \lambda_{\mathrm{ex}}=460 \mathrm{~nm}\right)$ and acidic $\left(I_{403}, \lambda_{\mathrm{ex}}=403 \mathrm{~nm}\right)$ forms of the HPTS probe as $\mathrm{pH}$ equilibration occurs.

(7) The $\mathrm{pH}$ conversion value is derived from fitting the plotted data (where $\mathrm{pH}$ is a function of the ratiometric data) to the adapted Henderson-Hasselbach equation (Equations (3) and (4) may be used for this purpose, see the HPTS sub-section of the Materials and Equipment section).

It is important to note that in HPTS selectivity assays, where the internal solution does not contain $\mathrm{NaCl}$, e.g., $\mathrm{NaX}^{\mathrm{IN}} / \mathrm{NaY}^{\mathrm{OUT}}$ conditions, the calibration procedure must be modified to use solutions containing the NaX salt of choice. 


\section{Data Treatment:}

\section{General:}

Typically, an HPTS experiment uses two cell holders; however, one is also possible while three is also commonplace for increased accuracy and data redundancy. Care should be taken as using more cell holders increases the time between recorded data and, therefore, decreases the data's 'resolution' and accuracy.

The procedures used in this section (unprocessed and software pre-processed, respectively) are produced from a general HPTS transport assay using the three systems below.

(1) HORIBA Scientific Fluoromax 4 Spectrophotometer is equipped with a KOOLANCE EXT-440 Liquid Cooling System and QUANTUM NORTHWEST TC 1 temperature controller, the FluorEssence 3.8.0.60 software in Origin 8.6.001 to acquire and process the data. Further data processing used both OriginPro 2021b (Academic) and Microsoft Excel 2019.

(2) Agilent Cary Eclipse Spectrofluorometer equipped with a stock temperature controller, multi-cell holder, collected data was processed using Agilent Cary Spectrofluorometer WinFLR Software 1.2(150) and the Cary Eclipse Ratio Application 1.2(146). Further processing used OriginPro 2021b (Academic) and Microsoft Excel 2019.

(3) HITACHI F-7000 Fluorescence Spectrophotometer equipped with a heating/cooling recirculating unit (Huber bath with an MPC controller), one cell holder and the FL Solutions 4.0 software to acquire the data.

Importantly, the data treatment process is repeated for each concentration of a tested transporter. Preliminary graphing of the acquired datasets shows whether the 
plotted HPTS data (HPTS traces) provide a reasonable spread across the transport range. A reasonable data spread consists of evenly spaced fluorometric readings, that when plotted, limit the space between each small incremental increase from the baseline produced from the DMSO control to the maximum recorded fluorescence intensity. However, in the event of an 'uneven' HPTS trace, refer to (13) of the Troubleshooting section.

\section{Transformation and normalisation of unprocessed data:}

Using the included spectrofluorometer software, the excitation (460 and $403 \mathrm{~nm}$ ) and emission $(510 \mathrm{~nm})$ wavelengths were pre-defined for multi-wavelength collection before the experiment was started. The recorded emission intensities at $510 \mathrm{~nm}$ by the basic $\left(I_{460}\right)$ and acidic $\left(I_{403}\right)$ HPTS forms were exported to a spreadsheet for further processing.

(1) Each fluorescence emission recorded for each sample was converted to a ratio using $\left(I_{460} / I_{403}\right)$. The normalised final fluorescence ratio value $\left(R_{\mathrm{f}}\right)$ is then calculated by averaging the last five fluorescence ratios of each dataset. These last five ratios correspond to the fluorometric probe emission after the vesicles had been lysed with detergent and ensure accuracy during normalisation.

(2) The normalised ratios are then converted using Equation (2) (previously defined in the HPTS sub-section of the Materials and Equipment section) to give the fractional fluorescence $\left(I_{\mathrm{f}}\right)$ intensity.

(3) The converted values calculated for each cuvette at time $t$ are averaged to produce a single dataset.

(4) The standard deviation of both normalised datasets at time $t$ is calculated using Equation (10): 


$$
\sigma=\sqrt{\frac{\sum(x-\bar{x})^{2}}{n}}
$$

where; $\sigma$ is the standard deviation of both samples, $x$ is the normalised values at time $t, \bar{x}$ is the mean of the normalised values, and $n$ is the number of normalised values.

During an experiment, the sample is excited at both 460 and $403 \mathrm{~nm}$ with a short delay (300 ms) between both excitations. After recording each samples emission intensity at $510 \mathrm{~nm}$ after each excitation, which some machines perform automatically, the software provides an $I_{460} / I_{403}$ ratio. Note: the wavelengths values should be predefined before starting the experiment in 'the method'. After each experiment is concluded (by adding detergent to lyse the vesicles), one dataset is obtained, which contains timestamps and the $I_{460} / I_{403}$ ratios. Conducting several assays during the day and over several days ensures the accuracy of the data. Then, average ratios can be normalised using Equation (2).

\section{Transformation and normalisation of software pre-treated data:}

Using multi-wavelength collection, the user-defined fluorescence emission at $510 \mathrm{~nm}$, produced from excitation wavelengths $460 \mathrm{~nm}$ and $403 \mathrm{~nm}$ (exciting the basic and acidic forms of HPTS, respectively), was recorded using two cell holders. The produced data was exported to a spreadsheet program. Due to pre-treatment from the fluorimeter software, the data was provided as ratiometric $\left(I_{460} / I_{403}\right)$ values; the data treatment process is simplified and uses a shortened procedure starting from step 3 of the Transformation and normalisation of unprocessed data sub-section under the Data Treatment section. 


\section{Calculation of EC $C_{50}$ values:}

(1) The recorded times, the averaged datasets calculated from the normalised raw data of both cuvettes in each experiment, and the respective standard deviation (y-error) are compiled within a spreadsheet program.

(2) With the time (s) set as the x-axis, the averaged ratios set as the y-axis and the standard deviation set as the y-error ( $\mathrm{yEr} \pm)$, the data was plotted as a line and symbol graph and rechecked for any irregularities before continuing.

(3) The values of each tested transporter concentration at $t=200 \mathrm{~s}$ (when the maximum transporter-mediated $\mathrm{H}^{+}$efflux has stabilised) were copied to a new worksheet where the transporter concentration was set as the x-axis, while the yaxis and y-error stayed the same before being plotted as a line and symbol graph.

(4) A non-linear curve fit was applied with the data points selected by selecting one of two user-defined Hill equations (Equation (11) or Equation (11) and the derived parameter from Equation (12)) in the non-linear curve fitting user dialogue. Using the default Levenberg-Marquardt iteration algorithm with default settings, the data was fitted until convergence.

Depending on the percentage of chloride efflux observed during the experiment, one of two functions can be used to perform non-linear curve fitting and calculate the $\mathrm{EC}_{50}$ value. Firstly, a system that has reached $100 \%$ chloride efflux can be fit using Equation (11):

$$
y=\frac{y_{0}+\left(y_{1}-y_{0}\right) \times x^{n}}{\left(k^{n}+x^{n}\right)}
$$


where; $x$ is the transporter concentration in $\mathrm{mol} \%, y_{0}$ is the first ratiometric value, $y_{1}$ is the last ratiometric value, $n$ is the Hill coefficient, and $k$ is the effective concentration of the transporter used to elicit $50 \%$ of the observed transport activity.

The calculated $\mathrm{EC}_{50}$ value $(k)$ will be correctly assigned to the concentration of the transporter (in mol\%), which exhibited $50 \%$ of the total $(100 \%)$ chloride efflux observed in the study. However, fitting the dataset of a transporter that does not reach $100 \%$ efflux, possibly due to poor transportability, issues with selectivity or solubility (see Troubleshooting section), will produce incorrect results. Instead, using non-linear curve fitting with Equation (11) in conjunction with the $\mathrm{EC}_{50}$ value, which has been set as a derived parameter (Equation (12)), the correct $\mathrm{EC}_{50}$ can be calculated:

$$
\mathrm{EC}_{50}=k \times\left(\frac{50}{y_{1}-y_{0}-50}\right)^{\frac{1}{n}}
$$

where; $y_{0}$ is the first ratiometric value, $y_{1}$ is the last ratiometric value, $n$ is the Hill coefficient, and $k$ is the effective concentration of the transporter used to elicit $50 \%$ of the observed transport activity. Due to the incomplete chloride efflux (not reaching the equilibrated or total chloride concentration in the system after the vesicles were lysed), an $\mathrm{EC}_{50}$ derived using the regular Hill equation would be incorrect. This is because rather than calculating the transporter concentration, which elicits $50 \%$ chloride efflux, the regular Hill equation would still calculate the transporter concentration, which elicits $50 \%$ of the maximum (100\%) transport.

\section{pH calculation:}

Alternatively, the ratiometric values can be converted to $\mathrm{pH}$. Depending on the preprocessing capabilities of the acquisition software, all unprocessed data must be converted to a ratio of $I_{460} / I_{403}$ following step 1 of the Transformation and 
normalisation of unprocessed data sub-section in the Data Treatment section.

(1) Both time datasets were averaged to give a single averaged time dataset.

(2) To two new columns and using the calibration constants, $a, b$, and $c$, during HPTS calibration with the modified Henderson-Hasselbach equation (see Equation (3) in the HPTS sub-section of the Materials and Equipment section), both sets of ratiometric values were converted to $\mathrm{pH}$ using the same equation (3) but substituting $x$ for the calculated ratiometric value instead. Alternatively, the Slogisticl model (Equation (4)) can also be used to transform ratiometric values (y) to $\mathrm{pH}(x)$ using the calibration constants $a, c$, and $k$.

(3) In two new columns, the normalised values, or $\Delta \mathrm{pH}$ values, were then calculated by subtracting the maximum initial $\mathrm{pH}$ value from the $\mathrm{pH}$ value at time $t$ using Equation (13):

$$
\Delta \mathrm{pH}=\left(\mathrm{pH}-\mathrm{pH}_{\mathrm{INI}}\right)
$$

where; $\mathrm{pH}_{\text {INI }}$ is the initial $\mathrm{pH}$ value (the $\mathrm{pH}$ value before transporter addition) while $\mathrm{pH}$ is the value at time $t$.

(1) The sorted $\Delta \mathrm{pH}$ values at time $t$ of the two datasets are then averaged to produce a single dataset.

(2) The standard deviation of the sorted $\Delta \mathrm{pH}$ values at time $t$ of both datasets was calculated following step 5 of the Transformation and normalisation of unprocessed data sub-section of the Data Treatment section.

(3) The averaged $\Delta \mathrm{pH}$ values were plotted as a function of the averaged times (s) with the corresponding standard deviation set as the y-error (yEr \pm ). 
However, it should be noted that although plotting the $\mathrm{pH}$ value against time might be perceived as a more straightforward way of representing the transport process, the $\mathrm{pH}$ value is not strictly proportional to the progress of $\mathrm{H}^{+}$transport. Gale and coworkers have shown experimentally that the $I_{460} / I_{403}$ value for the base-pulse assay is proportional to the progress of $\mathrm{H}^{+}$efflux, justifying the use of $I_{460} / I_{403}$ for quantitative purposes as mentioned in the previous section. ${ }^{41}$ On the other hand, the conversion of $I_{460} / I_{403}$ to $\mathrm{pH}$ values is preferred in the abovementioned anion gradient selectivity assays because the induced $\Delta \mathrm{pH}$ value is related to the permeability ratio of the intra and extra-vesicular anions. ${ }^{15}$ 


\section{Troubleshooting:}

What to do if:

(1) You pass the desired $\mathrm{pH}$ when balancing the $\mathrm{pH}$ of the buffer solutions (step 2 of Preparation of the required solutions).

If this happens, you can revert it by adding either an acid or base; however, this is not recommended since it can modify the ionic strength of the buffers. Therefore, it is better practice to prepare a new solution.

(2) You forget to pre-weigh the round-bottom flask containing the lipid (steps 2 and 5 of Vesicle preparation).

In this instance, calculation of the lipid concentration is not possible. Subsequently, the transporter to lipid ratio cannot be calculated; thus, the experimental results for that batch of vesicles are void.

(3) You lose some of the lipids during extrusion (steps 10 and $\mathbf{1 1}$ of Vesicle preparation).

In this case, note down the volume of lipid obtained after extrusion in order to recalculate the moles of lipid. Use Equations (5)-(8) from the Vesicle preparation subsection of the HPTS Transport Assay Experimental and Preparatory Procedures section to recalculate the number of moles you have. Also, to further safeguard against potential leaks from syringes when conducting extrusion, it is advisable to perform extrusion in a warm place; in this way, the expansion of the white Teflon (PTFE) spacing piece at the bottom of the syringe is favoured. 
(4) You are unable to distinguish vesicles from non-encapsulated HPTS when performing size-exclusion chromatography (step 14 of Vesicle preparation).

When this occurs, changing the room's light level (in our experience decreasing) or increasing the contrast between the more turbid encapsulated vs non-encapsulated HPTS by placing a piece of paper behind the column can help distinguish the HPTS encapsulated vesicles. ${ }^{63}$ The vesicles should be clearly identifiable during elution through the column as a milky green suspension, while the free HPTS is a bright green solution. In this regard, it is important only to collect the required volume of vesicles suspension, minimising the volume of eluent taken before and after.

(5) A part of non-encapsulated HPTS has eluted together with the lipids when carrying out size-exclusion chromatography (step 14 of Vesicle preparation).

In this case, check that the mass of G-25 Sephadex ${ }^{\circledR}$ is enough to run this separation and that there are no air bubbles throughout the column. If this happens, you should clean the Sephadex ${ }^{\circledR}$ completely with the external solution and then reseparate the collected vesicles, contaminated with non-encapsulated HPTS, through the size separation column. If the column is clean, in good condition, and the sample is added carefully (i.e., without disturbing the stationary phase), separation should be successful (as seen in Figure 10).

(6) Your transporter is not soluble in DMSO (step 4 of the Kinetic measurements sub-section).

If this happens, try preparing a more diluted solution of the transporter. If this does not work, you can try dissolving your transporter in another organic solvent in which it is fully soluble, provided the solvent is miscible with water. 
(7) You forget to start the timer when adding the transporter (step 4 of the Kinetic measurements sub-section).

This is only if the reading must be taken manually. If this happens, you are not recording the spectrofluorometer reading along with the experiment. In addition, it is not possible to know when the assay started and, consequently, when to add detergent to lyse the vesicles. Therefore, the results from that run are not valid.

(8) The addition of DMSO (or the solvent used to dissolve your carrier) induces a sharp increase in the spectrofluorometer reading (step 4 of the Kinetic measurements sub-section).

In this instance, you should clean the PTFE stirrer bar and the cuvette (if you are not using disposable cells) very well before continuing transport experiments to remove any possible contamination of other compounds. If the spectrofluorometer response is still significant after running a second blank, the vesicles are likely leaking. Therefore, the results obtained with that batch of leaky vesicles are not reliable. The experiment should be stopped, and a new batch of vesicles prepared. Leaking vesicles is not common and should not occur if the vesicle preparation procedure is followed closely.

(9) Your transporter precipitates when carrying out the assay (steps 4 to 6 of the Kinetic measurements sub-section).

If precipitation occurs, it is likely that your compound is poorly soluble in an aqueous solution and does not partition quickly into the membrane. You can prepare a more diluted solution and, if precipitation still occurs, you might try to pre-incorporate your transporter into the lipids during preparation. 
(10) The instrument reading during the experiment is higher than expected (steps 4 and $\mathbf{5}$ of the Kinetic measurements sub-section).

Should this occur, it is likely that your transporter strongly absorbs at either 403 or $460 \mathrm{~nm}$ (the excitation wavelengths of HPTS's protonated and deprotonated species, respectively), and the corresponding emission at $510 \mathrm{~nm}$ is significant. Since this effect is more problematic at higher concentrations, lower concentrations should be tested. If the problem persists, perhaps this assay is not suitable to analyse the activity of that transporter.

(11) You forget to add detergent to lyse the vesicles at the established time to end the assay (step 6 of the Kinetic measurements sub-section).

In this case, if you have not disposed of the sample, you can add the detergent to ascertain the equilibrium $I_{460} / I_{403}$ ratio (or equilibrium $\mathrm{pH}$ value). After $30 \mathrm{~s}$ the reading should be stable. However, it is desirable to add the detergent at the same time in all experiments.

(12) You leave the experiment running for longer than $30 \mathrm{~s}$ after adding the detergent (step 6 of the Kinetic measurements sub-section).

If this happens, stop the experiment. After lysing the vesicles, $30 \mathrm{~s}$ is usually the time required to obtain a stable reading from the instrument. It should be noted that, in order to maintain the consistency of the data, it is advisable to halt all the assays at the same time.

(13) You obtain uneven traces for a certain group of experiments (step 2 of the Calculation of $E C_{50}$ values section under Data Treatment). 
If one set of experimental data does not mimic the others, it can be due to either irregular or the absence of stirring inside the cuvette. This may cause irregular distribution of vesicles in solution, so the data from this assay is not comparable to other experimental datasets. Therefore, you should check that the stirring is on and, if possible, keep the same stirring speed throughout all assays.

(14) You cannot get reproducible results (step 2 and step 4 of the Calculation of $E C_{50}$ values section under Data Treatment).

This can be due to several reasons, for instance, the HPTS concentration. We have observed that the optimal fluorophore concentration is $1 \mathrm{mM}$ to get reproducible results reliably; the use of lower concentrations causes a decrease in the signal-to-noise ratio and, consequently, in repeatability. Also, you must ensure that all solutions have been prepared using the same conditions, namely, the same water quality, salts used, ionic strength, and temperature. This also applies to measurements (lipid and transporter concentrations in cuvettes, volumes taken from the stock or diluted solutions to perform the assays, and a consistent stirring speed during the experiments). It is advisable to do all the work in a room equipped, if possible, with air conditioning set at $25{ }^{\circ} \mathrm{C}(298 \mathrm{~K})$ and with the machine's temperature controller also set at $25^{\circ} \mathrm{C}(298 \mathrm{~K})$, and with accurately calibrated micropipettes. You should also check that the cuvettes are clean and dry before using them.

(15) The $\mathrm{pH}$ values resulting from applying the calibration equation differ from those obtained experimentally ( $\mathrm{pH}$ of the inner solution, equilibrium $\mathrm{pH}$ ) (step 2 of the Calculation of $\mathrm{pH}$ section under Data Treatment).

If this happens, you should check the conditions in which calibration (either with or without vesicles) was carried out. As mentioned above, experimental conditions must 
be as similar as possible during each experiment to minimise variations. The conditions to keep constant include the sodium salt employed, ionic strength of the solution, HPTS concentration, and temperature. If they are different, perform another calibration mimicking the conditions of the transport assays.

(16) You overshoot the equilibrium $\mathrm{pH}$ during an experiment (the Data Treatment section).

If the maximum $I_{460} / I_{403}$ ratio (or $\mathrm{pH}$ ) value reached by your transporter is higher than that obtained when adding a detergent, the concentration of the carrier solution might be too high. In this case, dilute the carrier solution to a lower concentration and retest.

(17) During the experiment, and again during data treatment, the addition of the transporter can produce a large initial jump followed by a slow increase (step 2 of the Data Treatment section and step 4 of the Kinetic measurements subsection under the HPTS Transport Assay Experimental and Preparatory Procedures section).

This large initial jump in the recorded ratiometric values is due to interference with HPTS response when the transporter is added to the cuvette. This interference must be excluded from the normalisation process as this does not represent the true membrane transport process. This interference is illustrated by an HPTS transport assay conducted with a previously reported tetrapodal anion transporter, tetraphenylurea, and shows the effect of including (Figure 11, Left) or excluding (Figure 11, Right) the interference. ${ }^{21}$ 

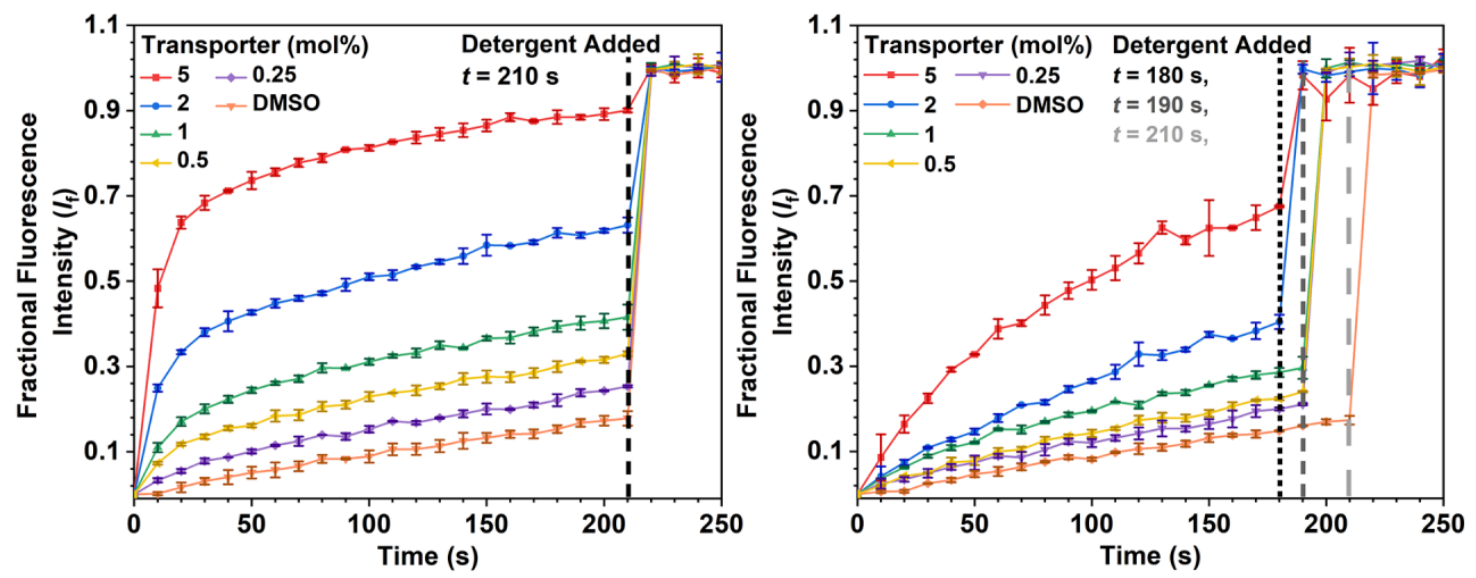

Figure 11. Shown in an HPTS transport assay using untreated vesicles and NMDG-Cl, the transporter (tetraphenylurea) can interfere with the fluorescence intensity and drastically affect the recorded data (Left). ${ }^{21}$ Removal of the interference in the same dataset reveals the skewed nature of the data, which is easily seen in the shifted times the vesicles were lysed (Right). The two highest concentrations, 2 and $5 \mathrm{~mol} \%$, took the longest to equilibrate ( $30 \mathrm{~s}$, black dotted line), followed by $1,0.5$, and $0.25 \mathrm{~mol} \%$ (20 s, grey short, dashed line), while the DMSO blank (light grey dashed line) was unaffected.

\section{Acknowledgements:}

A.M.G., P.W., X.W., and P.A.G. acknowledge and pay respect to the Gadigal people of the Eora Nation, the traditional owners of the land on which we research, teach, and collaborate at the University of Sydney.

\section{Disclosure Statement:}

The authors reported no potential conflict of interest.

\section{Funding:}

P.A.G. thanks the Australian Research Council (DP200100453) and the University of Sydney for funding. A.M.G. and P.W. thanks the Australian Government for their Research Training Program (RTP) scholarships. R.Q. gratefully acknowledges funding from the Consejería de Educación de la Junta de Castilla y León (project BU067P20) and Ministerio de Ciencia e Innovación (PID2020-117610RB-I00). D.A.-C. thanks Consejería de Educación de la Junta de Castilla y León for a predoctoral contract. 


\section{References:}

1. Busschaert, N.; Wenzel, M.; Light, M. E.; Iglesias-Hernández, P.; PérezTomás, R.; Gale, P. A., Structure-activity relationships in tripodal transmembrane anion transporters: the effect of fluorination. J. Am. Chem. Soc. 2011, 133 (35), 14136-14148.

2. Gadsby, D. C., Ion channels versus ion pumps: the principal difference, in principle. Nat. Rev. Mol. Cell Biol. 2009, 10 (5), 344-352.

3. Strange, K.; Emma, F.; Jackson, P. S., Cellular and molecular physiology of volume-sensitive anion channels. Am. J. Physiol. Cell Physiol. 1996, 270 (3), C711-C730.

4. Kim, J.-B., Channelopathies. Korean J. Pediatr. 2014, 57 (1), 1.

5. Sheppard, D. N.; Welsh, M. J., Structure and function of the CFTR chloride channel. Physiol. Rev. 1999, 79 (1), S23-S45.

6. Ko, S.-K.; Kim, S. K.; Share, A.; Lynch, V. M.; Park, J.; Namkung, W.; Van Rossom, W.; Busschaert, N.; Gale, P. A.; Sessler, J. L., Synthetic ion transporters can induce apoptosis by facilitating chloride anion transport into cells. Nat. Chem. 2014, 6 (10), 885-892.

7. Li, H.; Valkenier, H.; Thorne, A. G.; Dias, C. M.; Cooper, J. A.; Kieffer, M.; Busschaert, N.; Gale, P. A.; Sheppard, D. N.; Davis, A. P., Anion carriers as potential treatments for cystic fibrosis: transport in cystic fibrosis cells, and additivity to channel-targeting drugs. Chem. Sci. 2019, 10 (42), 9663-9672.

8. Chen, L.; Berry, S. N.; Wu, X.; Howe, E. N.; Gale, P. A., Advances in anion receptor chemistry. Chem 2020, 6 (1), 61-141.

9. Cossu, C.; Fiore, M.; Baroni, D.; Capurro, V.; Caci, E.; Garcia-Valverde, M.; Quesada, R.; Moran, O., Anion-transport mechanism of a triazole-bearing derivative of prodigiosine: A candidate for cystic fibrosis therapy. Front. Pharmacol. 2018, 9, 852.

10. Lisbjerg, M.; Valkenier, H.; Jessen, B. M.; Al-Kerdi, H.; Davis, A. P.; Pittelkow, M., Biotin[6]uril Esters: Chloride-Selective Transmembrane Anion Carriers Employing $\mathrm{C}-\mathrm{H} \cdots$ Anion Interactions. J. Am. Chem. Soc. 2015, 137 (15), 4948-4951. 
11. McNally, B. A.; Koulov, A. V.; Smith, B. D.; Joos, J.-B.; Davis, A. P., A fluorescent assay for chloride transport; identification of a synthetic anionophore with improved activity. Chem. Commun. 2005, (8), 1087-1089.

12. Schalley, C. A., Analytical methods in supramolecular chemistry. John Wiley \& Sons: 2012; Vol. 1.

13. Daleke, D. L.; Hong, K.; Papahadjopoulos, D., Endocytosis of liposomes by macrophages: binding, acidification and leakage of liposomes monitored by a new fluorescence assay. Biochim. Biophys. Acta 1990, 1024 (2), 352-366.

14. Jowett, L. A.; Gale, P. A., Supramolecular methods: The chloride/nitrate transmembrane exchange assay. Supramol. Chem. 2019, 31 (5), 297-312.

15. $\mathrm{Wu}, \mathrm{X}$; Gale, P. A., Measuring anion transport selectivity: a cautionary tale. Chem. Commun. 2021, 57 (33), 3979-3982.

16. Wu, X.; Gale, P. A., Small-molecule uncoupling protein mimics: synthetic anion receptors as fatty acid-activated proton transporters. J. Am. Chem. Soc. 2016, $138(50), 16508-16514$.

17. Kamp, F.; Zakim, D.; Zhang, F.; Noy, N.; Hamilton, J. A., Fatty acid flip-flop in phospholipid bilayers is extremely fast. Biochemistry 1995, 34 (37), 1192811937.

18. Wu, X.; Small, J. R.; Cataldo, A.; Withecombe, A. M.; Turner, P.; Gale, P. A., Voltage-Switchable $\mathrm{HCl}$ Transport Enabled by Lipid HeadgroupTransporter Interactions. Angew. Chem. Int. Ed. 2019, 58 (42), 15142-15147.

19. Wu, X.; Judd, L. W.; Howe, E. N.; Withecombe, A. M.; Soto-Cerrato, V.; Li, H.; Busschaert, N.; Valkenier, H.; Pérez-Tomás, R.; Sheppard, D. N., Nonprotonophoric electrogenic $\mathrm{Cl}^{-}$transport mediated by valinomycin-like carriers. Chem 2016, 1 (1), 127-146.

20. Gorteau, V.; Bollot, G.; Mareda, J.; Matile, S., Rigid-rod anion- $\pi$ slides for multiion hopping across lipid bilayers. Org. Biomol. Chem. 2007, 5 (18), 30003012.

21. Gilchrist, A. M.; Chen, L.; Wu, X.; Lewis, W.; Howe, E. N.; Macreadie, L. K.; Gale, P. A., Tetrapodal Anion Transporters. Molecules 2020, 25 (21), 5179.

22. Adriaenssens, L.; Estarellas, C.; Vargas Jentzsch, A.; Martinez Belmonte, M.; Matile, S.; Ballester, P., Quantification of Nitrate $-\pi$ Interactions and Selective Transport of Nitrate Using Calix[4]pyrroles with Two Aromatic Walls. J. Am. Chem. Soc. 2013, 135 (22), 8324-8330. 
23. Dawson, R. E.; Hennig, A.; Weimann, D. P.; Emery, D.; Ravikumar, V.; Montenegro, J.; Takeuchi, T.; Gabutti, S.; Mayor, M.; Mareda, J., Experimental evidence for the functional relevance of anion- $\pi$ interactions. Nat. Chem. 2010, 2 (7), 533-538.

24. Jentzsch, A. V.; Emery, D.; Mareda, J.; Nayak, S. K.; Metrangolo, P.; Resnati, G.; Sakai, N.; Matile, S., Transmembrane anion transport mediated by halogen-bond donors. Nat. Commun. 2012, 3 (1), 1-8.

25. Lee, L. M.; Tsemperouli, M.; Poblador-Bahamonde, A. I.; Benz, S.; Sakai, N.; Sugihara, K.; Matile, S., Anion transport with pnictogen bonds in direct comparison with chalcogen and halogen bonds. J. Am. Chem. Soc. 2019, 141 (2), 810-814.

26. Jentzsch, A. V.; Emery, D.; Mareda, J.; Metrangolo, P.; Resnati, G.; Matile, S., Ditopic ion transport systems: anion $-\pi$ interactions and halogen bonds at work. Angew. Chem. 2011, 123 (49), 11879-11882.

27. Jentzsch, A. V.; Matile, S., Transmembrane halogen-bonding cascades. J. Am. Chem. Soc. 2013, 135 (14), 5302-5303.

28. Saha, T.; Gautam, A.; Mukherjee, A.; Lahiri, M.; Talukdar, P., Chloride transport through supramolecular barrel-rosette ion channels: lipophilic control and apoptosis-inducing activity. J. Am. Chem. Soc. 2016, 138 (50), 1644316451.

29. Saha, T.; Hossain, M. S.; Saha, D.; Lahiri, M.; Talukdar, P., Chloridemediated apoptosis-inducing activity of bis (sulfonamide) anionophores. J. Am. Chem. Soc. 2016, 138 (24), 7558-7567.

30. Saha, T.; Dasari, S.; Tewari, D.; Prathap, A.; Sureshan, K. M.; Bera, A. K.; Mukherjee, A.; Talukdar, P., Hopping-mediated anion transport through a mannitol-based rosette ion channel. J. Am. Chem. Soc. 2014, 136 (40), 1412814135.

31. Burade, S. S.; Saha, T.; Bhuma, N.; Kumbhar, N.; Kotmale, A.; Rajamohanan, P. R.; Gonnade, R. G.; Talukdar, P.; Dhavale, D. D., Selfassembly of fluorinated sugar amino acid derived $\alpha, \gamma$-cyclic peptides into transmembrane anion transport. Org. Lett. 2017, 19 (21), 5948-5951.

32. Shinde, S. V.; Talukdar, P., Transmembrane $\mathrm{H}^{+} / \mathrm{Cl}^{-}$cotransport activity of bis(amido)imidazole receptors. Org. Biomol. Chem. 2019, 17 (18), 4483-4490. 
33. Martínez-Crespo, L.; Sun-Wang, J. L.; Ferreira, P.; Mirabella, C. F.; Aragay, G.; Ballester, P., Influence of the Insertion Method of Aryl-Extended Calix[4]pyrroles into Liposomal Membranes on Their Properties as Anion Carriers. Chem. Eur. J. 2019, 25 (18), 4775.

34. Li, Z.; Deng, L.-Q.; Chen, Y.; Wu, T.; Chen, W.-H., Efficient transmembrane anion transport mediated by a bis(imidazolyl)-functionalized bis(choloyl) conjugate. Bioorg. Med. Chem. Lett. 2016, 26 (15), 3665-3668.

35. Yu, X.-H.; Hong, X.-Q.; Chen, W.-H., Fluorinated bisbenzimidazoles: a new class of drug-like anion transporters with chloride-mediated, cell apoptosisinducing activity. Org. Biomol. Chem. 2019, 17 (6), 1558-1571.

36. Lu, Y.-M.; Deng, L.-Q.; Huang, X.; Chen, J.-X.; Wang, B.; Zhou, Z.-Z.; Hu, G.-S.; Chen, W.-H., Synthesis and anionophoric activities of dimeric polyamine-sterol conjugates: the impact of rigid vs. flexible linkers. Org. Biomol. Chem. 2013, 11 (47), 8221-8227.

37. Li, Z.; Chen, Y.; Yuan, D.-Q.; Chen, W.-H., Synthesis of a dimeric $3 \alpha-$ hydroxy-7 $\alpha, 12 \alpha$-diamino-5 $\beta$-cholan-24-oate conjugate and its derivatives, and the effect of lipophilicity on their anion transport efficacy. Org. Biomol. Chem. 2017, 15 (13), 2831-2840.

38. Cai, X.-J.; Li, Z.; Chen, W.-H., Tripodal squaramide conjugates as highly effective transmembrane anion transporters. Bioorg. Med. Chem. Lett. 2017, 27 (9), 1999-2002.

39. Akhtar, N.; Saha, A.; Kumar, V.; Pradhan, N.; Panda, S.; Morla, S.; Kumar, S.; Manna, D., Diphenylethylenediamine-based potent anionophores: Transmembrane chloride ion transport and apoptosis inducing activities. ACS Appl. Mater. Interfaces 2018, 10 (40), 33803-33813.

40. Das, S.; Biswas, O.; Akhtar, N.; Patel, A.; Manna, D., Multi-stimuli controlled release of a transmembrane chloride ion carrier from a sulfonium-linked procarrier. Org. Biomol. Chem. 2020, 18 (45), 9246-9252.

41. Clarke, H. J.; Wu, X.; Light, M. E.; Gale, P. A., Selective anion transport mediated by strap-extended calixpyrroles. J. Porphyr. Phthalocyanines 2020, 24 (01n03), 473-479.

42. Jowett, L. A.; Howe, E. N.; Soto-Cerrato, V.; Van Rossom, W.; Pérez-Tomás, R.; Gale, P. A., Indole-based perenosins as highly potent $\mathrm{HCl}$ transporters and potential anti-cancer agents. Sci. Rep. 2017, 7 (1), 1-11. 
43. Jowett, L. A.; Ricci, A.; Wu, X.; Howe, E. N.; Gale, P. A., Investigating the influence of steric hindrance on selective anion transport. Molecules 2019, 24 (7), 1278.

44. Spooner, M. J.; Li, H.; Marques, I.; Costa, P. M.; Wu, X.; Howe, E. N.; Busschaert, N.; Moore, S. J.; Light, M. E.; Sheppard, D. N., Fluorinated synthetic anion carriers: experimental and computational insights into transmembrane chloride transport. Chem. Sci. 2019, 10 (7), 1976-1985.

45. Carreira-Barral, I.; Mielczarek, M.; Alonso-Carrillo, D.; Capurro, V.; SotoCerrato, V.; Tomás, R. P.; Caci, E.; García-Valverde, M.; Quesada, R., Clicktambjamines as efficient and tunable bioactive anion transporters. Chem. Commun. 2020, 56 (21), 3218-3221.

46. Picci, G.; Carreira-Barral, I.; Alonso-Carrillo, D.; Sanz-González, D.; Fernández-López, P.; García-Valverde, M.; Caltagirone, C.; Quesada, R., Simple isophthalamides/dipicolineamides as active transmembrane anion transporters. Supramol. Chem. 2020, 32 (2), 112-118.

47. Gabba, M.; Frallicciardi, J.; van’t Klooster, J.; Henderson, R.; Syga, Ł.; Mans, R.; van Maris, A. J.; Poolman, B., Weak acid permeation in synthetic lipid vesicles and across the yeast plasma membrane. Biophys. J. 2020, 118 (2), 422-434.

48. Avanti Polar Lipids, I. https://avantilipids.com/product/840051 (accessed June 6, 2021).

49. Avanti Polar Lipids, I. https://avantilipids.com/product/241601 (accessed July $18,2021)$.

50. Saha, T.; Sengupta, A.; Hazra, P.; Talukdar, P., In vitro sensing of $\mathrm{Cu}^{+}$through a green fluorescence rise of pyranine. Photochem. Photobiol. Sci. 2014, 13 (10), 1427-1433.

51. Dansby-Sparks, R. N.; Jin, J.; Mechery, S. J.; Sampathkumaran, U.; Owen, T. W.; Yu, B. D.; Goswami, K.; Hong, K.; Grant, J.; Xue, Z.-L., Fluorescentdye-doped sol-gel sensor for highly sensitive carbon dioxide gas detection below atmospheric concentrations. Anal. Chem. 2010, 82 (2), 593-600.

52. Kocincova, A. S.; Borisov, S. M.; Krause, C.; Wolfbeis, O. S., Fiber-optic microsensors for simultaneous sensing of oxygen and $\mathrm{pH}$, and of oxygen and temperature. Anal. Chem. 2007, 79 (22), 8486-8493. 
53. Amdursky, N., Photoacids as a new fluorescence tool for tracking structural transitions of proteins: Following the concentration-induced transition of bovine serum albumin. Phys. Chem. Chem. Phys. 2015, 17 (47), 32023-32032.

54. Simón-Vázquez, R.; Lazarova, T.; Perálvarez-Marín, A.; Bourdelande, J. L.; Padrós, E., Cross-Linking of Transmembrane Helices Reveals a Rigid-Body Mechanism in Bacteriorhodopsin Transport. Angew. Chem. Int. Ed. 2009, 48 (45), 8523-8525.

55. Spry, D.; Goun, A.; Fayer, M. D., Deprotonation dynamics and Stokes shift of pyranine (HPTS). J. Phys. Chem. A 2007, 111 (2), 230-237.

56. Wolfbeis, O. S.; Fürlinger, E.; Kroneis, H.; Marsoner, H., Fluorimetric analysis. Fresenius' Zeitschrift für Analytische Chemie 1983, 314 (2), 119-124.

57. Davis, J. T.; Gale, P. A.; Quesada, R., Advances in anion transport and supramolecular medicinal chemistry. Chem. Soc. Rev. 2020, 49 (16), 6056-6086.

58. Han, J.; Burgess, K., Fluorescent indicators for intracellular pH. Chem. Rev. 2010, 110 (5), 2709-2728.

59. Wencel, D.; Abel, T.; McDonagh, C., Optical chemical pH sensors. Anal. Chem. 2014, 86 (1), 15-29.

60. Ulrich, S.; Osypova, A.; Panzarasa, G.; Rossi, R. M.; Bruns, N.; Boesel, L. F., Pyranine-Modified Amphiphilic Polymer Conetworks as Fluorescent Ratiometric pH Sensors. Macromol. Rapid Commun. 2019, 40 (21), 1900360.

61. Avanti Polar Lipids, I. https://avantilipids.com/divisions/equipmentproducts/mini-extruder-extrusion-technique (accessed October 14, 2021).

62. Yokouchi, Y.; Tsunoda, T.; Imura, T.; Yamauchi, H.; Yokoyama, S.; Sakai, H.; Abe, M., Effect of adsorption of bovine serum albumin on liposomal membrane characteristics. Colloids Surf. B. 2001, 20 (2), 95-103.

63. Wang, A.; Miller, C. C.; Szostak, J. W., Core-shell modeling of light scattering by vesicles: Effect of size, contents, and lamellarity. Biophys. J. 2019, 116 (4), 659-669. 